\title{
When the threat is stronger than the execution: trade and welfare under oligopoly
}

\author{
Dermot Leahy* \\ and \\ J. Peter Neary**
}

We compare the effects of changes in trade costs on trade volumes and on the gains from trade under Cournot and Bertrand competition. In both cases, the threshold trade costs below which the possibility of trade affects the domestic firm's behavior is the same; and welfare is U-shaped under reasonable conditions. However, welfare is typically greater under Bertrand competition; for higher trade costs the volume of trade is greater under Cournot competition, implying a "vander-Rohe Region"; and, for even higher trade costs, there exists a "Nimzowitsch Region", where welfare is higher under Bertrand competition even though no trade takes place.

\section{Introduction}

- The sign and magnitude of the gains from trade and from the easing of trade restrictions continue to be among the central issues in international trade. This is all the more so now that globalization is being challenged and trade costs are rising rather than falling in many markets. Recent work has thrown new light on the quantitative extent of these gains under perfect competition and monopolistic competition with heterogeneous firms (see, for example, Arkolakis, Costinot, and Rodríguez-Clare, 2012; Costinot and Rodríguez-Clare, 2014; Melitz and Redding, 2015; Arkolakis et al., 2018). However, far less is known about the effects of trade cost reductions in oligopolistic markets, despite growing evidence that trade is dominated by large firms (see, for example, Mayer and Ottaviano, 2008; Freund and Pierola, 2015).

In this article, we compare the effects of changes in trade costs under Cournot and Bertrand oligopoly in a common framework. The main objective is to set out the comparative effects of changes in trade costs on trade volumes and on the gains from trade under Cournot and Bertrand oligopoly. Under the general heading of trade costs we include transport costs, transaction costs,

\footnotetext{
* National University of Ireland Maynooth; Dermot.Leahy@mu.ie.

**University of Oxford; peter.neary@economics.ox.ac.uk.

The authors are grateful to the Central Bank of Ireland and the Royal Irish Academy for facilitating this research, and to Mark Armstrong, Volker Nocke, three anonymous referees and the editor for helpful comments. Peter Neary thanks the European Research Council for funding under the European Union's Seventh Framework Programme (FP7/2007-2013), ERC grant agreement no. 295669.
} 
and the cost of dealing with administrative and regulatory barriers to trade. Unlike tariffs these trade costs do not generate government revenue.

Some results of oligopoly models in trade and industrial organization are sensitive to the mode of competition. See, for example: Salant, Switzer, and Reynolds (1983) and Deneckere and Davidson (1985) on merger incentives; Vickers (1985), Fershtman and Judd (1987), and Sklivas (1987) on strategic delegation; and Brander and Spencer (1985) and Eaton and Grossman (1986) on strategic trade policy. ${ }^{1}$ Notwithstanding this, we show that many of the predictions about the effect of trade cost changes are qualitatively robust to whether firms compete in a Cournot or Bertrand manner. At the same time, there are important quantitative differences between the two models. This reflects the fact that firms compete more aggressively in the Bertrand than in the Cournot case.

We focus on a trade interpretation throughout, where a home firm faces foreign competitors that are penalized by a trade cost, and we want to understand the effects of changes in trade restrictiveness. However, our model also throws light on other problems in industrial organization. For example, the model can be reinterpreted as one with a technologically superior firm facing competitors that suffer from a cost disadvantage, where the interest lies in the effects of technological catch-up by the competing firms.

To focus attention on the nature of competition, and to allow us to derive explicit solutions for the outcomes we highlight, we first consider a symmetric multi-country world with linear demands and differentiated products. In this setting a single domestic firm faces competition in both home and foreign markets from many foreign firms. In this context, we show that the qualitative effects of a reduction in trade costs are common irrespective of the mode of competition. In particular, a fall in trade costs increases trade volume monotonically; welfare as a function of trade costs follows a U-shaped pattern; and there is a critical level of trade costs below which the possibility of trade affects the domestic firm's behavior, which is the same under Cournot and Bertrand competition.

On the other hand, there are important quantitative differences between the Cournot and Bertrand cases. For any trade cost below this critical level, welfare is higher under Bertrand than under Cournot competition. This makes intuitive sense, because Bertrand competition is more competitive than Cournot competition. Much less intuitive are the rankings of trade volumes. When trade costs are sufficiently low, we get the expected result where the volume of trade is always higher under Bertrand competition. However, for higher trade costs, imports are lower under Bertrand competition, though welfare remains higher. We call the region of parameter space in which this outcome holds the "van-der-Rohe Region," after the remark attributed to the architect Mies van der Rohe, "Less is more."2 More surprisingly still, for even higher trade costs, no trade takes place under Bertrand competition while the volume of trade is positive under Cournot. Nonetheless, the mere threat of trade under Bertrand competition is sufficient to discipline the home firm and is more effective in reducing prices and raising welfare than actual trade is under Cournot competition. We call the region of parameter space in which this outcome holds the "Nimzowitsch Region," after the remark attributed to the chess grandmaster Aron Nimzowitsch, "The threat is stronger than the execution." 3 Our article thus contributes to a literature that shows that the level of imports by itself is a poor measure of the extent to which home firms are exposed to foreign competition. ${ }^{4}$ Earlier work that discusses the region of parameter space in Bertrand competition in which a producing firm is disciplined by the presence of a non-producing rival include Clarke and Collie (2003) in a trade context and Zanchettin

${ }^{1}$ As Fudenberg and Tirole (1984) emphasize, the issue in these examples is whether firms' actions are strategic substitutes or complements rather than whether they engage in Cournot or Bertrand competition. As we shall see in Section 4, most of our results do not hinge on whether actions are strategic substitutes or complements.

${ }^{2}$ See en.wikipedia.org/wiki/Ludwig_Mies_van_der_Rohe.

${ }^{3}$ See en.wikipedia.org/wiki/Aron_Nimzowitsch.

${ }^{4}$ Holmes, Hsu, and Lee (2014) arrive at a similar finding in a different model with head-to-head Bertrand competition. See also recent empirical work by Bao and Chen (2018). 
(2006). ${ }^{5}$ Our focus is on the welfare properties of the region and we explore how the size of this region and the van-der-Rohe region are affected by the number of firms and the degree of product differentiation.

As noted, we first show that all these results hold in a multi-country model with linear demands. Subsequently, we allow for more general demand functions, and show that most of the results are qualitatively robust.

We focus throughout on a comparison between one-stage Cournot and Bertrand games. However, these can be interpreted as alternative outcomes to a two-stage game, as shown by Kreps and Scheinkman (1983) with identical products and by Maggi (1996) with differentiated products (see also Neary and Tharakan, 2012). In these models, firms first invest in capacity and then set their prices in a Bertrand manner. If the capacity cost is low enough, the outcome resembles a one-stage Bertrand game but if it is high enough it resembles a Cournot game. Hence our results can be interpreted as applying to a comparison between otherwise identical industries that differ in the ease with which they can adjust their capacity.

Our results build on and extend a large literature on the welfare effects of trade costs and trade liberalization under oligopoly. For overviews, see Leahy and Neary (2011) and Head and Spencer (2017). The topic was first studied by Brander (1981) and Brander and Krugman (1983) using a model of two-way trade in segmented markets. In this reciprocal-markets setting, they demonstrated that, under Cournot competition, intra-industry trade can occur in equilibrium even when goods are identical. Bernhofen (2001) introduced product differentiation into Cournot and Bertrand oligopoly models of intra-industry trade, focusing on the effects of trade on profits and consumer surplus. The effects of trade costs in related models have also been considered by Anderson, Donsimoni, and Gabszewicz (1989), Brander and Spencer (2015) and Collie and Le (2015). Clarke and Collie (2003), and Friberg and Gandslandt (2006, 2008) have explored gains from trade under Bertrand competition. ${ }^{6}$

Our article is the first to compare the effects of trade costs on trade volumes and on the gains from trade under Cournot and Bertrand oligopoly with general demands. Given reasonable restrictions on demand we show lower trade costs in the neighborhood of the prohibitive trade cost causes welfare to decline under both Cournot and Bertrand competition. We thus show that welfare under Cournot with high trade costs can be lower than welfare under autarky. However, under Bertrand competition there is a region of trade costs above the prohibitive trade cost where welfare rises under Bertrand competition as trade costs fall even though no trade takes place. With linear demands we go further and show that this implies that under Bertrand welfare never falls below the autarky level regardless of the number of countries or the degree of product differentiation. Thus with linear demands, for a range of trade costs, under Cournot but not under Bertrand, trade can lead to lower welfare than autarky when firms incur trade costs. Our setting also draws on an extensive literature in industrial organization. Our framework of a differentiatedproduct oligopoly where we compare Cournot and Bertrand behavior is similar to that of Singh and Vives (1984) and Vives (1985). However we have extended it to allow for asymmetric selling costs and corner solutions. Unlike work on entry deterrence and accommodation that builds on Dixit (1980) and Fudenberg and Tirole (1984), the effects that we identify arise in one-stage games where firms simultaneously choose their outputs or prices.

The plan of the article is as follows. Section 2 introduces the setting of a many-country reciprocal-markets model. Section 3 considers the linear multi-country version of the model and illustrates the effects of trade costs on outputs, trade volumes, and welfare under Cournot and Bertrand competition. Section 4 explores the case with general demands, and shows that the main results are robust. Section 5 concludes, while the Appendices give proofs of the main results.

\footnotetext{
${ }^{5}$ Zanchettin (2006) calls this region the limit pricing region in a closed economy model with asymmetric costs that compares profits under Cournot duopoly and Bertrand duopoly with linear demands.

${ }^{6}$ While Clarke and Collie (2003) show that welfare under Bertrand duopoly with linear demands is above the autarky level. Friberg and Gandslandt (2008) demonstrate that it is possible to have losses from trade in the Bertrand case with many firms and close substitutes if the autarky equilibrium is competitive enough.
} 


\section{The setting}

Throughout the article, we use a framework in which preferences and technology are independent of the mode of competition. There are $n \geq 2$ countries in the world, in each of which there is a single domestic firm producing a unique good and, except in autarky, competing against imports from foreign firms. Markets are segmented, so each firm's output may sell at different prices in different countries in equilibrium. The results we will highlight do not hinge on exogenous asymmetries between countries, so to avoid unnecessary notation we confine attention to the case where all firms face symmetric demands, the same production cost functions, and the same trade costs. This allows us to focus attention on a single representative country that we refer to as "home," and our main interest is to understand the endogenous asymmetries that arise as a result of trade costs.

On the demand side we assume a home representative consumer with quasi-linear utility:

$$
U=z_{0}+u(x, \mathbf{y})
$$

where $x$ is home sales of the home firm and $\mathbf{y}$ is the import vector with the sales of a typical foreign firm in the home market represented by $y_{j}$. Here $z_{0}$ is the consumption of the outside good which we assume is produced under perfect competition. This is a composite commodity defined over all the other goods in the economy, and we treat it as the numéraire good with a price equal to one. The sub-utility function $u(x, \mathbf{y})$ represents the domestic utility from consumption of the oligopolistic goods.

We can write the identity between national expenditure and national income as follows:

$$
z_{0}+p x+\mathbf{p}^{*} \cdot \mathbf{y}=I+\Pi
$$

Here $p$ is the home-market price of the goods produced by the home firm; $\mathbf{p}^{*}$ is the vector of home-market prices of the foreign firms; $I$ is domestic factor income; and $\Pi$ is the total profits of the home firm in all markets. As it is written, equation (2) assumes that trade costs do not yield any revenue. If instead they took the form of tariffs, then tariff revenue would appear as an additional term on the right-hand side of (2). (We briefly return to the issue of tariff revenue at the end of the next section.) We can make use of (2) in the utility function (1) to write home welfare as:

$$
W=U=\chi+\Pi+I
$$

where $\chi \equiv u(x, \mathbf{y})-p x-\mathbf{p}^{*} \cdot \mathbf{y}$ is a micro-founded expression for home consumer surplus. As is standard, we assume that the non-numéraire sector is small in factor markets and so we treat $I$ as constant.

On the cost side, we assume that marginal costs are constant and we ignore fixed costs. Hence the home and foreign firms' operating profits in the home market are:

$$
\pi=(p-c) x
$$

and

$$
\pi_{j}^{*}=\left(p_{j}^{*}-c-t\right) y_{j}
$$

where $c$ is the marginal production cost of the home and foreign firms, assumed to be constant, and $t$ is the per-unit trade cost.

\section{Linear demands and many countries}

Turning to the linear oligopoly case, we will first examine the effects of symmetric multilateral changes in trade costs under Cournot competition and then compare them with the outcome under Bertrand competition. We continue to assume that there is a single domestic firm in each country and that all firms have the same marginal cost of production and face the same trade cost 
of selling into the other markets. We first consider the case where all firms' sales are positive under both Cournot and Bertrand competition. We then turn to the case where imports are zero in equilibrium yet the best response of the home firm is to charge a lower price than it would in unconstrained autarky. We show that this occurs in the interval between the prohibitive trade cost threshold under Bertrand, $\widehat{t}^{B}$ and the corresponding prohibitive trade cost threshold under Cournot $\widehat{t}^{C}$, which is always non-empty and increases in the number of countries. The final step is to show that welfare is higher under Bertrand than under Cournot competition in this interval. Hence as discussed in the introduction it is a Nimzowitsch region.

A priori, the effect of an increase in the number of firms could go either way. On the one hand, more firms means that consumers enjoy more variety when imports occur. This tends to increase welfare under Cournot competition relative to Bertrand competition. On the other hand, more firms means more competition, including more incipient competition when imports do not occur. This forces the home firm to charge a lower price under Bertrand competition, which is clearly welfare-improving. It turns out that the competition effect dominates the variety effect, and by more the greater the number of firms.

There are $n$ countries in the world, in each of which there is a single domestic firm producing a unique good. Due to symmetry across countries, we can focus our analysis on a representative market. Thus we can restrict attention to the effect of a trade cost reduction on equilibrium in the home market. Define total import volume by: $Y=\sum_{j=1}^{n-1} y_{j}$. The sub-utility function for the oligopolistic goods from (1) takes the form:

$$
u(x, \mathbf{y})=a(x+Y)-\frac{1}{2} b\left(e(x+Y)^{2}+(1-e)\left(x^{2}+\sum_{j=1}^{n-1}\left(y_{j}\right)^{2}\right)\right)
$$

The parameter $b>0$ can be interpreted as an inverse measure of market size. As for $e$, it is an inverse measure of the degree of product differentiation, which we assume henceforward lies strictly between the cases of perfect substitutes $(e=1)$ and independent demands $(e=0)^{7}$. The inverse demand faced by the domestic firm and a representative foreign firm can be written as:

$$
p=a-b(x+e Y) \quad \text { and } \quad p_{j}^{*}=a-b\left(y_{j}+e x+e Y_{-j}\right)
$$

where $Y_{-j}=Y-y_{j}$. Firm profits are given by (4) and (5) as before. Hence the firms' first-order conditions under Cournot competition are $p-c+x \frac{\partial p}{\partial x}=0$ and $p_{j}^{*}-c-t+y_{j} \frac{\partial p_{j}^{*}}{\partial y_{j}}=0$ for all $j$, where $\frac{\partial p}{\partial x}=\frac{\partial p_{j}^{*}}{\partial y_{j}}=-b$ is the slope of the firms' inverse demand functions. The corresponding first-order conditions under Bertrand can be written as: $p-c+x\left(\frac{\partial x}{\partial p}\right)^{-1}=0$ for the home firm, and $p_{j}^{*}-c-t+y_{j}\left(\frac{\partial y_{j}}{\partial p_{j}^{*}}\right)^{-1}=0$ for a typical foreign firm, where $\frac{\partial x}{\partial p}=\frac{\partial y_{j}}{\partial p_{j}^{*}}=-\frac{1}{b} \frac{1+e(n-2)}{1+e(n-2)-e^{2}(n-1)}$ is the slope of the firms' direct demand functions. It is convenient to rewrite the home and foreign first-order conditions in a way that nests the Cournot and Bertrand special cases:

$$
\begin{gathered}
A-b(2+V) x-b(n-1) e y=0 \\
A-b(2+V+(n-2) e) y-b e x-t=0
\end{gathered}
$$

where we have made use of the fact that the outputs of every foreign firm are identical, allowing us to drop the subscript on $y$. The parameter $A \equiv a-c$ is the difference between the maximum price consumers are willing to pay and the marginal cost of production. In (8) and (9), we can interpret $V$ as a mode of competition or conduct parameter, though we are only interested in the

\footnotetext{
${ }^{7}$ We rule out the case of $e=1$ since it implies that no imports take place under price competition for any strictly positive trade cost. We rule out the case of $e=0$ since it implies that firms are independent monopolists with no strategic interaction.
} 
values it takes in Cournot and Bertrand competition. ${ }^{8}$ The conduct parameters under Cournot and Bertrand, respectively, are:

$$
V^{C}=0 \quad \text { and } \quad V^{B}=-\frac{(n-1) e^{2}}{1+(n-2) e}
$$

By inspection, $V^{B}<V^{C}$ for any $e>0$ and $V^{B}>-1$ for $e<1$. We show in Appendix A that $V^{B}$ is decreasing in $n$ and in $e$.

The first-order conditions in (8) and (9) can be solved for the equilibrium quantities. Sales by the home firm, and imports from a typical foreign firm are given by:

$$
x=x^{F}\left(1+(n-1) \frac{e}{2+V} \frac{t}{\widehat{t}}\right) \quad y=y^{F}\left(1-\frac{t}{\widehat{t}}\right)
$$

where

$$
x^{F}=y^{F}=\frac{A}{b \Gamma}, \quad \Gamma \equiv 2+V+(n-1) e, \quad \widehat{t} \equiv\left(1-\frac{e}{2+V}\right) A, \quad \text { and } \quad t \leq \widehat{t}
$$

Here $x^{F}$ and $y^{F}$ denote home sales and imports, respectively, in free trade; $\Gamma$ can be interpreted as a measure of the competitive pressure faced by an individual firm for a given value of $V ;{ }^{9}$ and $\widehat{t}$ denotes the prohibitive trade cost, that is, the minimum trade cost at which imports become zero. Note that, since $V$ varies with the mode of competition from (10), so also do $x^{F}, y^{F}, \Gamma$, and $\widehat{t}$; where necessary we use superscripts $C$ and $B$, for example, $x^{F C}, \widehat{t}^{B}$, etc., to denote Cournot and Bertrand competition, respectively. We are interested in comparing outputs and welfare under Cournot and Bertrand competition for different values of the trade cost $t$. The response of outputs to trade costs can be deduced immediately from (11): ${ }^{10}$

\section{Lemma 1. Irrespective of the number of countries:}

(a) In free trade, both home sales and imports are higher in Bertrand than in Cournot competition: $x^{F B}>x^{F C}$;

(b) Higher trade costs raise home sales and reduce imports irrespective of the form of competition: $\frac{\partial x}{\partial t}>0$ and $\frac{\partial y}{\partial t}<0$

(c) A rise in trade costs raises home sales by more and lowers imports by more in Bertrand than in Cournot competition: $\frac{\partial x^{B}}{\partial t}>\frac{\partial x^{C}}{\partial t}>0$ and $\frac{\partial y^{B}}{\partial t}<\frac{\partial y^{C}}{\partial t}<0$; and

(d) The prohibitive trade cost is lower in Bertrand than in Cournot competition: $\widehat{t}^{B}<\widehat{t}^{C}$.

Turning to the response of welfare to trade costs, it is clear that consumer surplus falls monotonically as trade costs rise. However, the response of profits is more complex. Focusing on the home firm, its total profits equals the sum of profits on home sales and the profits from exporting to $n-1$ foreign markets. The first are given by (4) while the second equal the foreign firms' profits in the home market because of the symmetry of the model, home exports $\sum_{j=1}^{n-1} x_{j}^{*}=(n-1) x^{*}$ equal home imports $\sum_{j=1}^{n-1} y_{j}=(n-1) y$, so the home firm's profits on its exports are $\left(p^{*}-c-t\right)(n-1) x^{*}=\left(p^{*}-c-t\right)(n-1) y$. Using the first-order conditions, maximized profits are equal to $b(1+V) x^{2}$ from home sales and $(n-1) b(1+V)\left(x^{*}\right)^{2}$ from exports.

${ }^{8}$ This can also be seen as a conjectural variations parameter. See, for example, Dixit (1986). Although conjectural variations are now seen as an unsatisfactory way of modelling strategic interaction in general when interpreted as a conduct parameter $V$ provides a useful way of comparing Cournot and Bertrand behavior on a common basis.

${ }^{9}$ This interpretation follows as in Mrázová (2011), because, for a given value of $V, \Gamma$ is increasing in the number of firms $n$ and in the degree of substitutability $e$ : increases in either of these make the environment each firm faces more competitive and so tend to reduce individual firm output. For more details see Appendix A.

${ }^{10}$ These results and many subsequent ones are stated as strict, which follows from our assumption that $e$ lies strictly between zero and one. 
Total profits for the home firm are then equal to the sum of these, and their behavior as trade costs change can be shown to equal:

$$
\begin{aligned}
\frac{\partial \Pi}{\partial t} & =2 b(1+V)\left(x \frac{\partial x}{\partial t}+(n-1) x^{*} \frac{\partial x^{*}}{\partial t}\right) \\
& =\frac{2(n-1)}{2+V} \frac{p^{F}-c}{\widehat{t}}\left(e x-(2+V) x^{*}\right) \quad\left\{\begin{array}{l}
<0 \text { when } t=0\left(\operatorname{so} x=x^{*}\right) \\
>0 \text { when } t=\widehat{t}\left(\operatorname{so} x^{*}=0\right)
\end{array}\right.
\end{aligned}
$$

where $p^{F}-c=b(1+V) x^{F}$ is the firms' price-cost margin in free trade. Profits are decreasing in trade costs at free trade, but increasing in them in the neighborhood of the prohibitive trade cost $\widehat{t}$. Hence, it follows that profits must be a U-shaped function of trade costs, irrespective of the mode of competition. ${ }^{11}$ The same must be true of welfare. At free trade, both consumer surplus and profits are falling in trade costs. As for autarky, the fall in consumer surplus is not enough to offset the rise in home profits for an infinitesimal increase in trade costs: $d \chi=-x d p$ (since $y=0$ at autarky) and $d \Pi=(p-c) d x+x d p$ (since $y=x^{*}=0$ and $p^{*}=c+t$ ). The sum of these reduces to $d W=(p-c) d x$ and we know from part (b) of Lemma 1 that home sales are increasing in trade costs. Hence it follows that welfare is also increasing in trade costs in the neighborhood of autarky. Summarizing:

Lemma 2. Assume $0<e<1$. Then welfare is a U-shaped function of trade costs under both Cournot and Bertrand competition.

This lemma is a multi-country oligopoly generalization of the U-shaped welfare results of Brander and Krugman (1983) for Cournot competition and Clarke and Collie (2003) for Bertrand competition. Having established how welfare depends on trade costs, we next want to compare the levels of welfare in Cournot and Bertrand competition.

Consider first the range of trade costs consistent with positive imports under both types of competition, which, from part (d) of Lemma 1 , is $0 \leq t \leq \widehat{t}^{B}$. We want to show that, in this range, welfare is always higher under Bertrand than under Cournot competition for given values of $e$, $n$ and $t$. Welfare equals the utility level given by (6), evaluated in equilibrium where all foreign firms have equal sales, minus production and trade costs:

$$
W(x, Y)=A(x+Y)-\frac{1}{2} b\left(e(x+Y)^{2}+(1-e)\left(x^{2}+\frac{1}{n-1} Y^{2}\right)\right)-t Y
$$

where $Y=(n-1) y$ because of symmetry. We can differentiate this with respect to $V$ as a simple way of comparing the Cournot and Bertrand cases, since $V^{C}$ is unambiguously greater than $V^{B}$ from (10):

$$
\frac{d W(x, Y)}{d V}=W_{x} \frac{d x}{d V}+W_{Y} \frac{d Y}{d V}=\left(W_{x}-W_{Y}\right) \frac{d x}{d V}+W_{Y} \frac{d Q}{d V}
$$

where $Q$ denotes total sales in the home market: $Q=x+Y$. It is easy to check that sales of the home firm, and total sales in the home market, are both decreasing in $V$; hence they are higher in Bertrand than in Cournot competition. (Details are in Appendix A.) Similarly, it is immediate that, in the relevant range, welfare increases in both $x$ and $Y$ : intuitively, increases in either of these partially overcome the oligopoly distortion. As for the effect of an equal and opposite change in $x$ and $Y$, this has a negative effect on welfare by reducing variety, but also a positive effect through a saving in trade costs. It turns out that the latter effect dominates so $W_{x}>W_{Y} \cdot{ }^{12}$ Combining these results, we see that welfare is decreasing in $V$. This gives our first key result:

\footnotetext{
${ }^{11}$ For the special case of Cournot competition in duopoly (13) takes a particularly simple form: $\frac{\partial \Pi}{\partial t}=\frac{p^{F}-c}{\hat{t}}(e x-$ $\left.2 x^{*}\right)$.

${ }^{12}$ From equation (A6) in Appendix A, the difference $W_{x}-W_{Y}$ equals the dumping margin, the difference between the price charged at home, $p$, and the f.o.b. price received from exporting, $p^{*}-t$.
} 
Proposition 1. For trade costs in the range $0 \leq t \leq \widehat{t}^{B}$, welfare is strictly higher in Bertrand competition than in Cournot competition: $W^{B}>\bar{W}^{C}$, for $e>0$.

Surprisingly, the unambiguous ranking of welfare levels under different modes of competition does not carry over to the levels of imports in the range $0 \leq t \leq \widehat{t}^{B}$. From part (a) of Lemma 1, we know that imports in free trade are higher under Bertrand competition than under Cournot competition, while from part (d) imports at the upper point of the range $\widehat{t}^{B}$ are lower under Bertrand competition than under Cournot competition. Since imports are linear in $t$ from (11), there must be an intermediate trade $\operatorname{cost} t^{R}, 0 \leq t^{R} \leq \widehat{t}^{B}$, at which imports are the same under the two modes of competition:

$$
t^{R}:\left.\quad y^{B}\right|_{t=t^{R}}-\left.y^{C}\right|_{t=t^{R}}=0
$$

Hence imports must be lower under Bertrand competition than under Cournot competition for all $t$ such that $t^{R}<t<\widehat{t}^{B}$. Substituting for outputs from (11), we can express $t^{R}$ in terms of freetrade imports under each form of competition, $y^{F B}$ and $y^{B C}$, and the two prohibitive trade costs:

$$
t^{R}=\frac{\left(y^{F B}-y^{F C}\right) \hat{t}^{C}}{y^{F B} \hat{t}^{C}-y^{F C} \hat{t}^{B}} \hat{t}^{B}
$$

By inspection, this is less than $\widehat{t}^{B}$. It can be shown that $t^{R}$ is decreasing in both $n$ and $e$ : see Appendix A. Combining these results with Proposition 1, we can conclude:

Proposition 2. The non-empty interval $\left(t^{R}, \widehat{t}^{B}\right)$ is a van-der-Rohe Region in which welfare is strictly higher but imports are strictly lower under Bertrand competition than under Cournot competition: $W^{B}>W^{C}$ and $0<y^{B}<y^{C}$, for $0<e<1$. The lower boundary of this interval, $t^{R}$, is decreasing in the number of firms $n$ and the degree of substitutability $e$.

Finally, we want to consider what happens for trade costs in the interval $\left(\widehat{t}^{B}, \widehat{t}^{C}\right)$. Consider first the size of the interval. Since $V=0$ under Cournot, $\widehat{t}^{C}=\frac{2-e}{2} A$ is independent of the number of countries. As for $\widehat{t}^{B}$, it is increasing in $V^{B}$ which is decreasing in $n$ as we have seen, and so overall it is falling in $n$. It follows that as the number of countries increases the interval between the two prohibitive trade costs gets larger. It can also be shown that this interval is increasing in the degree of substitutability $e$ : see Appendix A.

The final part of the proof is to show that welfare is higher under Bertrand competition in the interval $\left(\widehat{t}^{B}, \widehat{t}^{C}\right)$; in other words, that this interval is indeed a Nimzowitsch Region. We show this in three steps, the details of which are given in Appendix A. Let $W^{N}$ represent $W^{B}$ in the interval $\left(\widehat{t}^{B}, \widehat{t}^{C}\right)$. First, we show that $W^{N}-W^{C}$ is quadratic and concave in $t$ everywhere. This implies that a sufficient condition for $W^{N}-W^{C}$ to be positive throughout the region is that it is non-negative at the end-points of the region. Next, we can show that $W^{N}$ is equal to $W^{C}$ at the upper end of the region, $t=\widehat{t}^{C}$, where no trade occurs and the home firm is an unconstrained monopolist in both Bertrand and Cournot competition. Finally, we can show that $W^{N}$ is equal to $W^{B}$ at the lower end, where $t=\widehat{t}^{B}$, since welfare depends only on outputs, and at that point outputs under unconstrained Bertrand competition, $x^{B}$ and $y^{B}$, are equal to those under constrained Bertrand competition, $x^{N}$ and $y^{N}$ (with $y^{N}=y^{B}=0$ ). Since we know from Proposition 2 that $W^{B}$ is greater than $W^{C}$ at that point, it follows that $W^{N}$ is also greater than $W^{C}$.

Hence, it follows that welfare is always greater under Bertrand than under Cournot competition throughout the $\left.\widehat{t}^{B}, \widehat{t}^{C}\right)$ region, so it is indeed a Nimzowitsch Region. Summarizing our results:

Proposition 3. The non-empty interval $\left(\widehat{t}^{B}, \widehat{t}^{C}\right)$ is a Nimzowitsch Region in which welfare is higher under Bertrand competition than under Cournot competition: $W^{N}>W^{C}$; while imports 
FIGURE 1

REGIONS OF TRADE AND WELFARE IN DUOPOLY

[Color figure can be viewed at wileyonlinelibrary.com]

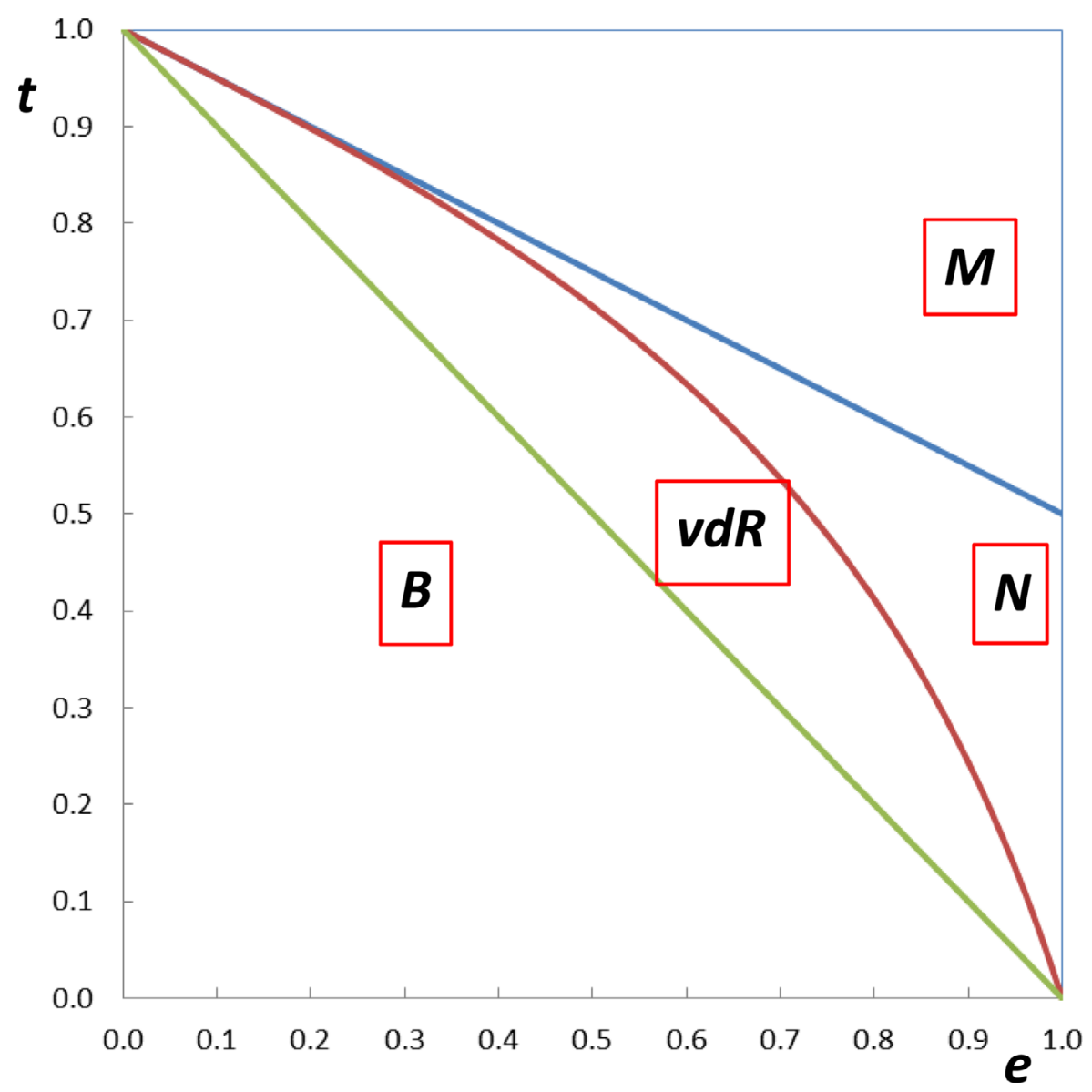

Notes: The three loci show the values of $\hat{t}^{C}, \hat{t}^{B}$ and $t^{R}$ (in decreasing order as functions of $e$ )

B: Bertrand yields higher Trade and Welfare, $y^{B}>y^{C}>0, W^{B}>W^{C}$

vdR: van-der-Rohe Region, $y^{C}>y^{B}>0, W^{B}>W^{C}$

$\mathrm{N}$ : Nimzowitsch Region, $y^{C}>y^{B}=0, W^{B}>W^{C}$

M: Unconstrained Monopoly, $y^{C}=y^{B}=0$

are positive under Cournot competition and zero under Bertrand competition. The width of this region is increasing in the number of firms $n$ and the degree of substitutability $e$.

Figure 1 shows how the sizes of the different regions vary with the degree of substitutability $e$ and the trade cost $t$ (normalized by $A$ ) for the canonical case of duopoly. Figure 2 illustrates Propositions 1, 2, and 3. The three panels repeat the loci from Figure 1 for values of $n$ equal to 4,12 and 24, respectively. They show clearly that, as the number of countries increases, the Nimzowitsch Region expands slowly, whereas the B region contracts substantially. As $n$ grows without bound, the lower boundary of the Nimzowitsch Region asymptotes to $2 \frac{1-e}{2-e}$, while the lower boundary of the van-der-Rohe Region expands to such an extent that the B region is fully crowded out. (See Appendix A.) For very large numbers of firms, there are almost no parameter values for which Bertrand competition yields higher imports, yet it always yields higher welfare. 


\section{FIGURE 2}

REGIONS OF TRADE AND WELFARE IN OLIGOPOLY FOR DIFFERENT VALUES OF $n$

[Color figure can be viewed at wileyonlinelibrary.com]

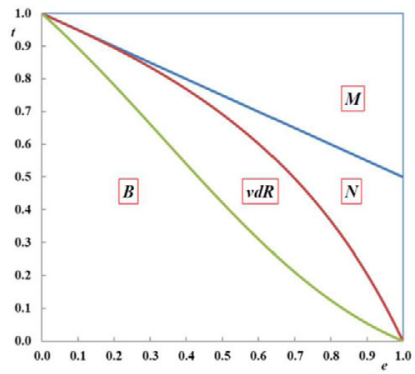

(a) $n=4$

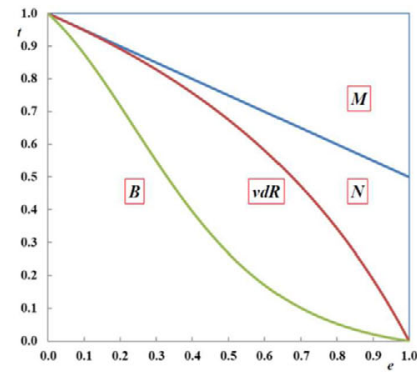

(b) $n=12$

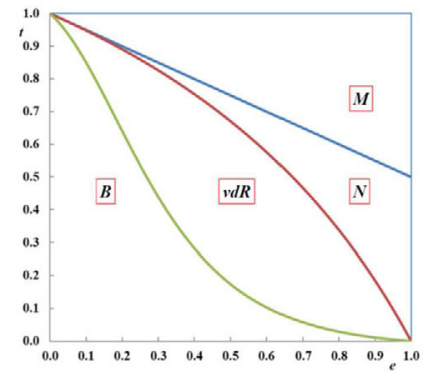

(c) $n=24$

Notes: See figure 1 for legend.

Since welfare is U-shaped under Cournot for $t<\widehat{t}^{C}$ from Lemma 2 we know that welfare falls below the autarky level for some levels of the trade cost. Is that also true under Bertrand competition? Under Bertrand competition welfare is U-shaped in the interval $\left[0, \widehat{t}^{B}\right]$. However, welfare at $\widehat{t}^{B}$ is above that in unthreatened autarky. Despite this apparent ambiguity it turns out that we are able to obtain the following clear result:

Proposition 4. Under Cournot competition but not under Bertrand competition the minimum welfare level with trade is below the welfare level under autarky.

This proposition is a generalization of the results of Brander and Krugman (1983) and Clarke and Collie (2003) to the case of a multi-country oligopoly. Losses from trade in this linear model arise from the presence of wasteful trade costs. (Total trade costs $t Y(t)$ follow an inverted U-shape in the per-unit trade cost.) However, this source of losses from trade is not present when tariff revenue is costlessly returned to consumers. When no tariff revenue is lost, trade liberalization in the form of tariff reductions, never leads to welfare with trade falling below that in autarky regardless of the mode of competition ${ }^{13}$.

\section{General demands}

- We now consider welfare under general demands and discuss the extent to which the results obtained in the previous section are dependent on the assumption of linear demands. We will show that many of the results are qualitatively robust. Figure 3 highlights the properties that we will show are robust when we switch from linear to general demands. We begin with some preliminary discussion of the properties of general demands and their implications for firm behavior. Following this, we consider the effects of changes in trade costs on outputs and welfare in free trade and in autarky. We then show that the novel insights from earlier continue to hold: both a van-der-Rohe Region and a Nimzowitsch Region always exist. To avoid unnecessary notation, we restrict attention to the canonical case of duopoly.

Properties of general demands. We write inverse demands as $p(x, y)$ for the home good and $p^{*}(y, x)$ for the foreign. We impose some mild regularity assumptions on these demands.

\footnotetext{
${ }^{13}$ In the presence of tariff revenue, unlike when it is absent, it can be shown that welfare under Cournot and Bertrand are both monotonically decreasing and globally concave in $t$ below the prohibitive level.
} 


\section{FIGURE 3}

WELFARE AND TRADE COSTS WITH GENERAL DEMANDS

[Color figure can be viewed at wileyonlinelibrary.com]

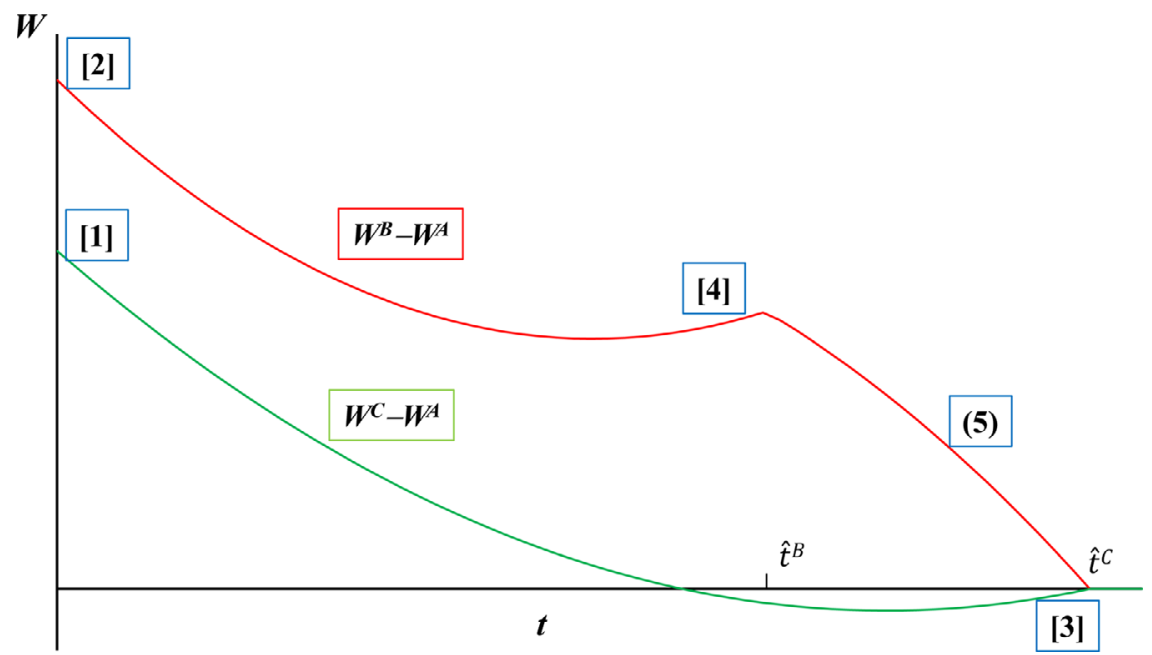

Notes: The numbers in parentheses correspond to the numbered results given later in the text.

First, we assume that the demand functions are twice differentiable and strictly downwardsloping: $p_{x}<0$ and $p_{y}^{*}<0$. Next, we assume that the goods are substitutes: $p_{y}<0$ and $p_{x}^{*}<0$. Finally, we assume that demand for the imported good has a choke price: $\lim _{y \rightarrow 0} p^{*}(y, x)<\infty$. This assumption guarantees the existence of a prohibitive trade cost that eliminates all imports, which in turn is a necessary condition for the existence of a Nimzowitsch Region, as we show below. The assumption is consistent with linear demands as in the previous section, and also with many of the other demand functions used in applied economics. It rules out the case where consumers have an infinite reservation price for the first unit purchased, as for example with iso-elastic or logistic demand. Thus we rule out Dixit-Stiglitz preferences which do not yield a choke price or a prohibitive trade cost. ${ }^{14}$

We also assume that the demand functions are symmetric, in the sense that their levels and first and second derivatives are equal when evaluated at the same point:

$$
\left.\begin{array}{c}
p\left(x_{0}, y_{0}\right)=p^{*}\left(y_{1}, x_{1}\right) \\
p_{i}\left(x_{0}, y_{0}\right)=p_{j}^{*}\left(y_{1}, x_{1}\right), i, j=x, y, i \neq j \\
p_{x i}\left(x_{0}, y_{0}\right)=p_{y j}^{*}\left(y_{1}, x_{1}\right), i, j=x, y, i \neq j
\end{array}\right\} \text { when: } x_{0}=y_{1} \text { and } y_{0}=x_{1}
$$

Finally, we assume that the inverse demand system can be inverted to get the direct demands:

$$
x=x\left(p, p^{*}\right) \text { and } y=y\left(p^{*}, p\right)
$$

For this inversion to be possible, we require that own-price effects in demand dominate crossprice effects, in the sense that $e e^{*}<1$, where $e(x, y) \equiv p_{y} / p_{x}$ and $e^{*}(x, y) \equiv p_{x}^{*} / p_{y}^{*}$ are inverse measures of product differentiation for the home and foreign demand functions, respectively. ${ }^{15}$ Our assumption that goods are substitutes ensures that both $e$ and $e^{*}$ are strictly positive.

\footnotetext{
${ }^{14}$ Requiring that demand must have a choke price for the Nimzowitsch Region to exist is in line with Vives (1985), following Friedman (1977).

${ }^{15}$ Inverting the inverse demand functions to yield well-behaved direct demand functions requires that $p_{x} p_{y}^{*}-$ $p_{x}^{*} p_{y}>0$, which from the definitions of $e$ and $e^{*}$ implies that $\left(1-e e^{*}\right) p_{x} p_{y}^{*}>0$.
} 
Firm behavior in interior equilibria. In this section, we consider the responses of imports and domestic sales when both firms sell positive amounts in either Cournot or Bertrand competition. The home firm's profit function can be written as a function of either quantities or prices: $\pi(x, y)=[p(x, y)-c] x$ or $\pi\left(p, p^{*}\right)=(p-c) x\left(p, p^{*}\right)$. We assume that both functions are quasi-concave in the firm's own action, and have a unique maximum given the foreign firm's action. We also assume that all equilibria are stable, which requires that own effects dominate cross effects at the margin:

Assumption 1. $\Delta \equiv \pi_{x x} \pi_{y y}^{*}-\pi_{x y} \pi_{y x}^{*}>0$ and $\widetilde{\Delta} \equiv \pi_{p p} \pi_{p^{*} p^{*}}^{*}-\pi_{p p^{*}} \pi_{p^{*} p}^{*}>0$.

This in turn implies:

Lemma 3. $\pi_{x x}+\pi_{x y}=2 p_{x}+p_{y}+x\left(p_{x x}+p_{x y}\right)<0$ when outputs are equal $(x=y)$; and $\pi_{p p}+$ $\pi_{p p^{*}}=2 x_{p}+x_{p^{*}}+(p-c)\left(x_{p p}+x_{p p^{*}}\right)<0$ when prices are equal $\left(p=p^{*}\right)$.

The proof is immediate. In quantity competition when outputs are equal, $\Delta$ equals $\left(\pi_{x x}\right)^{2}-$ $\left(\pi_{x y}\right)^{2}=\left(\pi_{x x}+\pi_{x y}\right)\left(\pi_{x x}-\pi_{x y}\right)>0$. There are two cases to consider. Either outputs are strategic substitutes, $\pi_{x y}<0$, in which case $\pi_{x x}+\pi_{x y}<0$ follows immediately, which implies that $\pi_{x x}-$ $\pi_{x y}$ must also be negative. Alternatively, outputs are strategic complements, $\pi_{x y}>0$, in which case $\pi_{x x}-\pi_{x y}<0$, which implies that $\pi_{x x}+\pi_{x y}$ must also be negative. ${ }^{16}$ This lemma implies that own effects dominate cross effects at the margin in a different sense: home marginal revenue falls following an equal increase in the outputs of both goods, and the marginal responsiveness of home profits to own price falls following an equal increase in the prices of both goods. Finally, for some (though not all) of the results that follow, we need an additional mild restriction on the home firm's profits as a function of outputs:

Assumption 2. $\pi_{x x}=2 p_{x}+x p_{x x}<0$ holds everywhere.

Assumption 2 is stronger than requiring the second-order condition to hold: it is equivalent to the home firm's marginal revenue being always downward-sloping. This means that the demand function can be convex, but not too much so.

Turning to the production side, we continue to assume identical constant marginal production costs $c$ and per-unit trade costs $t$. Hence, under monopoly, the home firm has first-order condition:

$$
\pi_{x}=p\left(x^{M}, 0\right)+x^{M} p_{x}\left(x^{M}, 0\right)-c=0
$$

where $x^{M}$ is the monopoly output, and $p\left(x^{M}, 0\right)=p^{M}$ is the monopoly price.

Under Cournot competition, the home and foreign firm's first-order conditions are:

$$
\pi_{x}=p(x, y)+x p_{x}(x, y)-c=0 \text { and } \pi_{y}^{*}=p^{*}(y, x)+y p_{y}^{*}(y, x)-c-t=0
$$

Differentiating these gives the responses of sales to trade costs when both firms sell positive amounts:

$$
\frac{d x^{C}}{d t}=\frac{\pi_{x y}}{\Delta} \lessgtr 0 \text { and } \quad \frac{d y^{C}}{d t}=\frac{\pi_{x x}}{\Delta}<0
$$

recalling that $\Delta$ is positive from Assumption 1. Hence an increase in the trade cost always reduces the volume of imports, while it raises domestic sales if and only if the goods are strategic substitutes $\left(\pi_{x y}=p_{y}+x p_{x y}<0\right)$.

Under Bertrand competition, the firms' first-order conditions are:

$$
\pi_{p}=(p-c) x_{p}\left(p, p^{*}\right)+x=0 \text { and } \pi_{p^{*}}^{*}=\left(p^{*}-c-t\right) y_{p^{*}}\left(p^{*}, p\right)+y=0
$$

\footnotetext{
${ }^{16}$ An analogous proof holds in Bertrand competition.
} 
For later use, it is very helpful to rewrite these in terms of inverse rather than direct demands and their derivatives; this will facilitate comparison with the corresponding Cournot firstorder conditions in (21). To do this, we can use footnote 15 to write $x_{p}=\frac{p_{y}^{*}}{p_{x} p_{y}^{*}-p_{y} p_{x}^{*}}=\frac{1}{p_{x}} \frac{1}{1-e e^{*}}$ and $y_{p^{*}}=\frac{p_{x}}{p_{x} p_{y}^{*}-p_{y} p_{x}^{*}}=\frac{1}{p_{y}^{*}} \frac{1}{1-e e^{*}}$. Substituting into (23) allows us to write the two firms' first-order conditions under Bertrand competition expressed in terms of inverse demands: ${ }^{17}$

$$
p(x, y)+x p_{x}\left(1-e e^{*}\right)-c=0 \quad \text { and } \quad p^{*}(y, x)+y p_{y}^{*}\left(1-e e^{*}\right)-c-t=0
$$

Returning to (23), differentiating shows that the effects of trade costs on prices are: $d p^{B} / d t=$ $-\left(y_{p^{*}} / \widetilde{\Delta}\right) \pi_{p p^{*}}$, which is positive if and only if prices are strategic complements; and $d p^{* B} / d t=$ $\left(y_{p^{*}} / \widetilde{\Delta}\right) \pi_{p p}$ which is always positive. (Again, recall that $\widetilde{\Delta}$ must be positive from Assumption 1.) These price derivatives can be combined with the derivatives of (19) to obtain the effects of trade costs on outputs:

$$
\frac{d x^{B}}{d t}=\frac{y_{p^{*}}}{\widetilde{\Delta}}\left(x_{p^{*}} \pi_{p p}-x_{p} \pi_{p p^{*}}\right) \quad \text { and } \quad \frac{d y^{B}}{d t}=\frac{y_{p^{*}}}{\widetilde{\Delta}}\left(y_{p^{*}} \pi_{p p}-y_{p} \pi_{p p^{*}}\right)
$$

The natural case is where these effects are positive and negative, respectively: higher trade costs raise home output and restrict imports. Unlike the Cournot case in (22), the latter outcome is not guaranteed. However, it must hold if own effects on demand and marginal profits dominate cross effects $\left(\left|y_{p^{*}}\right|>\left|y_{p}\right|\right.$ and $\left.\left|\pi_{p p}\right|>\left|\pi_{p p^{*}}\right|\right)$. Henceforward we assume that $\frac{d y^{B}}{d t}$ is negative, so that trade costs reduce imports. The former outcome, $\frac{d x^{B}}{d t}>0$, is not guaranteed by dominant own effects. A sufficient condition for it to hold is that prices are not too strongly strategic complements.

Armed with these preliminary results, we can now turn to consider their implications for the robustness of the results derived in the previous section for linear demands.

Zero trade costs. At $t=0$ the sales of the home and foreign firm are equal. Thus under Cournot, $x^{C}=y^{C}$, and under Bertrand, $x^{B}=y^{B}$, where $C$ and $B$ denote the Cournot and Bertrand equilibria, respectively. We can write the first-order condition for the home and foreign firms under Cournot at $t=0$ as $\pi_{x}\left(q^{C}\right)=\pi_{y}^{*}\left(q^{C}\right)=0$, where $q=x=y$ is the symmetric output which is at the level $q^{C}$ in the zero trade cost Cournot equilibrium. From (24), the first-order condition under Bertrand can be written as $\pi_{x}\left(q^{B}\right)+\beta\left(q^{B}\right)=0$, where $q^{B}$ represents the symmetric output at the zero trade cost Bertrand equilibrium, and where $\beta(q)=-x p_{x} e e^{*}=-y p_{y}^{*} e e^{*}$ is positive at any $q>0$. Since $\beta(q)$ is positive everywhere we have: $\pi_{x}\left(q^{B}\right)<0$ but $\pi_{x}\left(q^{C}\right)=0$ and since $\pi_{x}(q)$ falls in $q$ from Lemma 3 it follows that: $q^{B}>q^{C}$. Therefore, at zero trade costs, the volume of trade is higher under Bertrand than Cournot competition. It must also be the case that prices at free trade are lower under Bertrand than Cournot. Finally, it is easy to show that welfare is monotonically increasing in output in a symmetric free-trade equilibrium. ${ }^{18}$ Hence at zero trade costs welfare is higher in Bertrand than in Cournot competition. Summarizing: ${ }^{19}$

Lemma 4. At free trade, Bertrand competition leads to lower prices, higher trade volume, and higher welfare than Cournot competition.

Next, we want to compare the responsiveness of welfare to trade costs at free trade under the two forms of competition. We first derive a general expression for the change in welfare. Recall from expression (3) above that welfare is the sum of consumer surplus and home profits.

\footnotetext{
${ }^{17}$ The same outcome would be obtained if we assumed that the firms have "Bertrand conjectural variations": for example, the home firm conjectures that, if it increases its output, the foreign firm's output will change so as to exactly offset the home firm's impact on the foreign price. Recall the discussion in footnote 8.

${ }^{18}$ Evaluating welfare from equation (3) in symmetric free trade gives: $\left.W\right|_{t=0}=u(x, x)-2 c x+I$. Differentiating gives $\left.\frac{d W}{d x}\right|_{t=0}=2\left(u_{x}-c\right)=2(p-c)$. This is strictly positive given that there is an oligopoly distortion.

${ }_{19}^{19}$ The results on prices and trade volume are implicit in Vives (1985).
} 
The change in consumer surplus is: $d \chi=-\left(x d p+y d p^{*}\right)$ and the change in the profits of the home firm is: $d \Pi=(p-c) d x+x d p+\left(p^{*}-c-t\right) d x^{*}+x^{*} d p^{*}-x^{*} d t$. Combining these and making use of the symmetry of the model which implies that home exports $x^{*}$ equal home imports $y$, we can write the change in welfare as:

$$
d W=d \chi+d \Pi=(p-c) d x+\left(p^{*}-c-t\right) d y-y d t
$$

Thus consumption of home and imported goods have a positive effect on welfare, while wasteful trade costs have an additional negative effect.

Consider next the welfare effect of an increase in trade costs starting at free trade $(t=0)$. Irrespective of the mode of competition, (26) simplifies in this case to:

$$
\left.\frac{d W^{h}}{d t}\right|_{t=0}=(p-c)\left(\frac{d x^{h}}{d t}+\frac{d y^{h}}{d t}\right)-y, \quad h=C, B
$$

It can be shown that total domestic consumption $x+y$ is unambiguously decreasing in trade costs at free trade under both Cournot and Bertrand competition. Detailed derivations are given in Appendix B. Hence we can conclude that

$$
\text { [1] }\left.\frac{d W^{C}}{d t}\right|_{t=0,+}<0 \quad \text { [2] }\left.\frac{d W^{B}}{d t}\right|_{t=0,+}<0
$$

which confirms the result found in the linear case. Summarizing:

Lemma 5. Starting at free trade, an increase in trade costs lowers welfare under both Cournot and Bertrand competition.

Prohibitive trade costs. Next we turn to the case of prohibitive trade costs. We first show that they must be lower under Bertrand than under Cournot competition. We can write the Cournot equilibrium output pair as a function of the trade cost as $\left\{x^{C}(t), y^{C}(t)\right\}$. The equilibrium level of imports in the Cournot case reaches zero at the threshold prohibitive trade cost, $\widehat{t}^{C}$. Let $\widehat{x}^{C}=x^{C}\left(\widehat{t}^{C}\right)$ and $\left.\widehat{y}^{C}=y^{C} \widehat{t}^{C}\right)=0$ be the Cournot equilibrium outputs at $\widehat{t}^{C}$. At the prohibitive trade cost the Cournot first-order conditions given in (21) can be written as $p\left(\widehat{x}^{C}, 0\right)+\widehat{x}^{C} p_{x}\left(\widehat{x}^{C}, 0\right)-c=0$ and $p^{*}\left(0, \widehat{x}^{C}\right)-c-\widehat{t}^{C}=0$ for the home and foreign firm, respectively. At the prohibitive trade cost the home first-order condition takes exactly the same form as under monopoly, so, from (20), we have $\widehat{x}^{C}=x^{M}$. Making use of this allows us to write: $\widehat{t}^{C}=p^{*}\left(0, x^{M}\right)-c$. This means that, if the trade cost were at $t=\widehat{t}^{C}$ and the home firm were to behave as an unconstrained monopolist, the foreign firm's trade-cost-inclusive price-cost margin would be zero and the foreign firm would be unable to export profitably.

Consider next the case of Bertrand competition. Let $\widetilde{t}^{B}$ be the threshold prohibitive trade cost under Bertrand. Write the Bertrand equilibrium outputs at $\widehat{t}^{B}$ as: $\widehat{x}^{B}=x^{B}\left(\widehat{t}^{B}\right)$ and $\widehat{y}^{B}=y^{B}\left(\widehat{t}^{B}\right)=$ 0 . At $\widehat{t}^{B}$, the first-order conditions under Bertrand given in (24) can be written as $p\left(\widehat{x}^{B}, 0\right)+$ $\widehat{x}^{B} p_{x}\left(\widehat{x}^{B}, 0\right)-c+\beta\left(\widehat{x}^{B}, 0\right)=0$ for the home firm, where $\beta=-x p_{x} e e^{*}$, and as $p^{*}\left(0, \widehat{x}^{B}\right)-c-$ $\widehat{t}^{B}=0$ for the foreign firm. Since $\beta>0$ it follows that: $p\left(\widehat{x}^{B}, 0\right)+\widehat{x}^{B} p_{x}\left(\widehat{x}^{B}, 0\right)-c<0$. Making use of this and Assumption 2 we get: $\widehat{x}^{B}>\widehat{x}^{C}=x^{M}$. It then follows that $\widehat{t}^{B}=p^{*}\left(0, \widehat{x}^{B}\right)-c<$ $p^{*}\left(0, \widehat{x}^{c}\right)-c=\widehat{t}^{c}$. Summarizing: ${ }^{20}$

Lemma 6. The prohibitive trade cost is lower under Bertrand than under Cournot competition: $\widehat{t}^{B}<\widehat{t}^{C}$.

\footnotetext{
${ }^{20}$ Both threshold trade costs are unique: $\widehat{t}^{C}$ from (22), and $\widehat{t}^{B}$ from (25) given our assumption that $d y^{B} / d t$ is always negative.
} 
Next, consider the effect of a small fall in trade costs on welfare starting at the prohibitive level. At this point we have $p^{*}-c-t=0$ and $y=x^{*}=0$, which from (26) imply:

$$
\left.\frac{d W^{h}}{d t}\right|_{t=\hat{t}^{h},-}=(p-c) \frac{d x^{h}}{d t}, \quad h=C, B
$$

The effect of trade costs on outputs in interior equilibria have been derived above: see equations (22) and (25). Substituting these into (29) gives:

$$
\text { [3] }\left.\frac{d W^{C}}{d t}\right|_{t=\hat{t}^{C},-}=-\frac{p-c}{\Delta} \pi_{x y} \quad \text { [4] }\left.\frac{d W^{B}}{d t}\right|_{t=\hat{t}^{B},-}=-\frac{p-c}{\widetilde{\Delta}}\left(x_{p} \pi_{p p^{*}}-x_{p^{*}} \pi_{p p}\right) y_{p^{*}}
$$

Inspecting these expressions and recalling equations (22) and (25), we can conclude that:

Lemma 7. Starting at the relevant prohibitive trade cost, a reduction in trade costs lowers welfare under Cournot competition if and only if outputs are strategic substitutes; and it lowers welfare under Bertrand competition provided prices are not too strongly strategic complements.

These results are indicated by the points denoted [3] and [4] in Figure 3.

The van-der-Rohe region. Next we want to show that there exists a van-der-Rohe Region, that is, a subset of trade costs at which welfare is higher but imports are lower in Bertrand than in Cournot competition.

The first step is to show that there must exist at least one trade cost at which imports are equal under the two modes of competition. We know from Lemma 4 that at free trade imports are higher under Bertrand competition, and we know from Lemma 6 that at the prohibitive trade cost $\widehat{t}^{B}$ they are zero under Bertrand competition and strictly positive under Cournot competition. Hence, since imports are always continuous in trade costs, we can conclude that:

Lemma 8. There exists at least one trade cost, $t^{R} \in\left(0, \widehat{t}^{B}\right)$, at which the volume of imports is the same in both Cournot and Bertrand competition.

Start with the case where there is a unique trade cost, $t^{R}$, at which the volume of imports is the same. Hence, it must be true that an infinitesimal increase in the trade cost must yield higher imports under Cournot than under Bertrand competition. To see this, let $y^{R}$ denote the level of imports under both forms of competition when the trade cost equals $t^{R}$. We can then show that home sales must be higher under Bertrand competition. Consider the response of home profits to a small increase in home sales when imports equal $y^{R}$ :

$$
\pi_{x}\left(x, y^{R}\right)=p\left(x, y^{R}\right)+x p_{x}\left(x, y^{R}\right)-c
$$

In Cournot competition, we know from the first-order condition (21), evaluated at the equilibrium level of home sales which we call $x^{C R}$, that the expression in (31) is zero: $\pi_{x}\left(x^{C R}, y^{R}\right)=0$. By contrast, in Bertrand competition, we know from the first-order condition (24) that it must be strictly negative:

$$
\pi_{x}\left(x^{B R}, y^{R}\right)=p\left(x^{B R}, y^{R}\right)+x^{B R} p_{x}\left(x^{B R}, y^{R}\right)-c=x^{B R} p_{x}\left(x^{B R}, y^{R}\right) e e^{*}<0
$$

where $x^{B R}$ denotes the level of home sales in the Bertrand equilibrium. Recalling from Assumption 2 that the home firm's marginal profit is always decreasing in home sales, this implies that home sales are strictly higher under Bertrand than under Cournot competition. Since imports are the same, this in turn implies that welfare is strictly higher. It follows that a small increase in $t$ 
will lead to higher imports but lower welfare under Cournot than under Bertrand competition. ${ }^{21}$ Hence there exists a van-der-Rohe Region in the right-hand-side neighborhood of $t^{R}$.

Next, consider the possibility that there are many trade costs at which imports are the same under both forms of competition. Assume that such trade costs arise from multiple but separated intersection points of the two functions giving imports as a function of trade costs. (We rule out the theoretical curiosum of a continuum of intersections.) It then follows that the number of such intersections cannot be even, and that in the neighborhood of each odd intersection the argument just given for the case of a unique $t^{R}$ continues to apply. Hence we can conclude:

Proposition 5. There must exist a (not necessarily connected) van-der-Rohe Region; that is, a subset of trade costs at which imports are lower but welfare is higher under Bertrand than under Cournot competition.

The Nimzowitsch region. The final step is to prove the existence of a Nimzowitsch region. With general demands, this requires two distinct conditions. First, "threat" and "execution" must coexist: there must exist a range of trade costs such that, under Bertrand competition, imports are zero and the equilibrium price is below the autarky level, while, under Cournot competition, imports are strictly positive. We call this "import contestability." By itself it corresponds to a weak version of a Nimzowitsch region, since welfare is higher under Bertrand competition than in autarky, even though no imports take place. However, for the strong version of a Nimzowitsch region we require in addition a second condition: the threat must be "superior" to the execution, meaning that welfare must be higher under Bertrand competition than under Cournot competition. With general demands we cannot expect to prove that this holds throughout the region in which import contestability holds, but we can prove it holds for a small fall in trade costs in the neighborhood of autarky. We call this "local superiority of Bertrand competition." We consider these two conditions in turn.

Formally we can define import contestability as follows:

Definition 1. Import Contestability: Imports are strictly positive under Cournot competition, $y^{C}>0$, and zero under Bertrand competition, $y^{B}=0$, with $p^{B}<p^{M}$.

We wish to show that import contestability holds if and only if trade costs are in the interval $\left(\widehat{t}^{B}, \widehat{t}^{C}\right)$. (Recall that both thresholds are unique and, from Lemma 6 , that the interval between them is non-empty: $\widehat{t}^{B}<\widehat{t}^{C}$.) To show this, we consider in turn trade costs outside and inside this range.

First, it is immediate that import contestability cannot hold for trade costs outside the interval. For trade costs lower than $\widehat{t}^{B}$, imports under Bertrand competition are strictly positive: $y^{B}>0$ for $t \in\left[0, \widehat{t}^{B}\right)$. While for trade costs equal to or higher than $\widehat{t}^{C}$, imports under Cournot competition are zero: $y^{C}=0$ for $t \geq \widehat{t}^{C}$. In both cases, one or other of the conditions for import contestability is violated.

Second, we turn to explore what happens in the interval $\left(\widehat{t}^{B}, \widehat{t}^{C}\right)$. It is immediate that imports are strictly positive under Cournot competition, $y^{C}>0$, in this range, since we have seen in equation (22) that imports under Cournot competition are strictly decreasing in trade costs below autarky, $\frac{d y^{C}}{d t}<0$ for $t \in\left[0, \widehat{t}^{C}\right]$. It remains to prove that, under Bertrand competition, the other two conditions for import contestability hold in this range: the equilibrium level of imports is zero, $y^{B}=0$, and the equilibrium price is lower than that of an unconstrained monopolist, $p^{B}<p^{M}$. To do this, we must consider the properties of the Nash equilibrium in the Bertrand game.

${ }^{21}$ We ignore the contrived case where (32) holds, so welfare is strictly higher in Bertrand than in Cournot competition at $t^{R}, W^{C R}<W^{B R}$, but only infinitesimally so, and, for an infinitesimal increase in the trade cost above $t^{R}$, the welfare levels in Cournot and Bertrand competition are equal. 


\section{FIGURE 4}

IMPORT CONTESTABILITY IN THE BERTRAND GAME [Color figure can be viewed at wileyonlinelibrary.com]

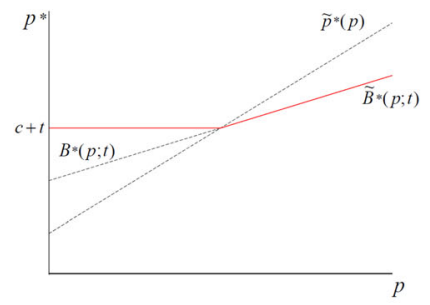

(a) Foreign Best-Response Function

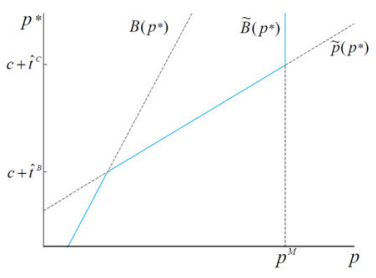

(b) Home Best-Response Function

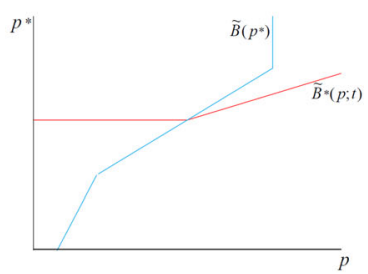

(c) Equilibrium

Consider first the foreign best-response function. This is illustrated in Figure 4(a). In an interior Bertrand equilibrium (where imports are strictly positive), the foreign firm's best-response function is: $p^{*}=B^{*}(p ; t)=\operatorname{argmax}_{p^{*}} \pi^{*}\left(p^{*}, p ; t\right)$. However, if the home firm's price falls to a level where the zero-import constraint binds, then the foreign firm's best response is to charge a price equal to its marginal cost of serving the market, $c+t{ }^{22}$ Hence the foreign best-response function is simply $p^{*}=c+t$, in anticipation of zero sales, and $B^{*}(p, t)$ when the home price is high enough that the foreign firm anticipates positive sales; with the threshold between the two given by the locus $\widetilde{p}^{*}(p)$ defined implicitly by $y\left(p, \widetilde{p}^{*}\right)=0$. Combining these two regimes, the foreign firm's best-response function is:

$$
p^{*}=\tilde{B}^{*}(p, t)= \begin{cases}c+t & \text { when } \tilde{p}^{*}(p) \leq B^{*}(p ; t) \\ B^{*}(p ; t) & \text { when } \tilde{p}^{*}(p) \geq B^{*}(p ; t)\end{cases}
$$

This locus intersects the zero-import locus, and is shown by the bold locus in Figure 4(a)

In the same way, we can examine the best responses of the home firm. First, for low import prices, the home firm's best response is also to charge a low price along its unconstrained bestresponse function $B\left(p^{*}\right)=\operatorname{argmax}_{p} \pi\left(p, p^{*}\right)$. Consider next the home firm's best-response function when $t \in\left(t^{B}, \widehat{t}^{C}\right)$. We wish to show that the home firm's best response is to set its own price at a level $\tilde{p}$ such that the zero-import constraint, $y\left(\tilde{p}, p^{*}\right)=0$, just binds. We can write the domestic price at which the zero-import constraint just binds as $\widetilde{p}\left(p^{*}\right)$ for $t \in\left(\widehat{t}^{B}, \widehat{t}^{C}\right)$. First, note that $\widetilde{p}\left(p^{*}\right)$ is monotonically increasing (since goods are substitutes, so $y_{p}$ is positive). Next, note that $\widetilde{p}\left(p^{*}\right)$ equals the monopoly price at the upper bound of the range, $\widetilde{p}\left(p^{*}\right)=p^{M}$ when $p^{*}=c+\widehat{t}^{C}$. This reflects the fact that the prohibitive trade cost in Cournot competition, $\widehat{t}^{c}$, equals the threshold level of trade costs at or above which the home firm can act as an unconstrained monopolist under Bertrand competition. It follows from this and from the monotonicity of $\tilde{p}$ in $p^{*}$ that $\tilde{p}(c+t)$ must be less than $p^{M}$ for $t<\widehat{t}^{C}$.

Next, to show that $\widetilde{p}\left(p^{*}\right)$ is the best-response function for $t \in\left(\widehat{t}^{B}, \widehat{t}^{C}\right)$, consider price deviations by the home firm. This can be illustrated with the help of 4(b). First, consider price reductions from $\tilde{p}\left(p^{*}\right)$. Such reductions in the home firm's price while keeping imports at zero would lower the home firm's profits, since $\widetilde{p}\left(p^{*}\right) \leq p^{M}$, profits are maximized at $p^{M}$, and profits are quasi-concave in $p$. Next, consider an upward deviation in the price from $\tilde{p}\left(p^{*}\right)$. The home firm's interior Bertrand best-response function can only intersect once with $\widetilde{p}\left(p^{*}\right)$. This follows from the assumption that $y_{p^{*}} \pi_{p p}-y_{p} \pi_{p p^{*}}>0$ (see equation (25) and the subsequent discussion). The slope $d p / d p^{*}$ of the home firm's interior Bertrand best-response function, $B\left(p^{*}\right)$, is less

${ }^{22}$ Following most of the literature, we rule out cases where firms, in anticipation of zero sales, set price below marginal cost. For an alternative view and references see Erlei (2002). 
than the slope $d p / d p^{*}$ of the zero-import locus, $\widetilde{p}\left(p^{*}\right)$, at the point where they intersect, where $p^{*}=c+\widehat{t}^{B} \cdot{ }^{23}$ This means that $\tilde{p}\left(p^{*}\right)$ cannot be on the upward-sloping part of $\pi\left(p, p^{*}\right)$. That is, $\pi_{p}(\tilde{p}(c+t), c+t) \leq 0$ for $t \geq \widehat{t}^{B}$. Thus an increase in the home firm's price from $\widetilde{p}\left(p^{*}\right)$ would lead to imports $(y>0)$ and result in the home firm's profits falling. Hence $\tilde{p}\left(p^{*}\right)$ is the bestresponse function for $t \in\left(\widehat{t}^{B}, \widehat{t}^{C}\right)$. The home firm's best-response function is:

$$
p=\tilde{B}\left(p^{*}\right)= \begin{cases}B\left(p^{*}\right) & \text { when } \tilde{p}\left(p^{*}\right) \leq B\left(p^{*}\right) \\ \tilde{p}\left(p^{*}\right) & \text { when } B\left(p^{*}\right) \leq \tilde{p}\left(p^{*}\right) \leq p^{M} \\ p^{M} & \text { when } p^{M} \leq \tilde{p}\left(p^{*}\right)\end{cases}
$$

This function is shown by the bold locus in Figure 4(b).

Finally, we can bring together the responses of the two firms to show the full equilibrium, as in Figure 4(c). Import contestability holds for $t \in\left(\widehat{t}^{B}, \widehat{t}^{C}\right)$ : imports are zero, $y^{B}=0$, the foreign firm sets the price $p^{* B}=c+t$, and the home firm prices below the monopoly level, $p^{B}<p^{M}$. Summarizing:

Lemma 9. Import contestability, $y^{C}>0, y^{B}=0$, and $p^{B}<p^{M}$, holds throughout the interval $t \in\left(\hat{t}^{B}, \widehat{t}^{C}\right)$.

Consider next the second property, local superiority of Bertrand competition:

Definition 2. Local Superiority of Bertrand Competition: $W^{C}<W^{B}$ in the neighborhood of $t=\widehat{t}^{c}$; that is,

$$
\left.\frac{d W^{C}}{d t}\right|_{t=t^{C},-}>\left.\frac{d W^{B}}{d t}\right|_{t=t^{C},-}
$$

To show that this holds, consider first the case of Bertrand competition. In this case we can show that welfare is decreasing in trade costs throughout the relevant region and not just at $t=\widehat{t}^{C}$. This is because, as we have seen, imports are zero, and the foreign firm sets its price equal to $c+t$. Because imports are zero, the change in welfare for a small reduction in trade costs depends only on the change in consumption of the home good:

$$
\left.\frac{d W^{B}}{d t}\right|_{t \in\left(\hat{t}^{B}, \hat{t}^{C}\right)}=\left.(p-c) \frac{d x^{B}}{d t}\right|_{t \in\left(\hat{t}^{B}, \hat{t}^{C}\right)}
$$

And, because of the firm's pricing behavior, a fall in trade costs results in an increase in home output sufficient to keep imports equal to zero:

$$
p^{*}(0, x)=c+\left.t \Rightarrow \frac{d x^{B}}{d t}\right|_{t \in\left(\hat{t}^{B}, \hat{t}^{C}\right)}=\frac{1}{p_{x}^{*}(0, x)}
$$

This must be negative, since foreign output is a substitute for home output, which gives the desired result: ${ }^{24}$

$$
\text { [5] }\left.\frac{d W^{B}}{d t}\right|_{t \in\left(\hat{t}^{B}, \hat{t}^{C}\right)}<0
$$

Consider next the case of Cournot competition. Note first that, in the neighborhood of autarky, a small change in imports is valued at $p^{*}-c-t$ which is zero. Hence, in quantity competition,

\footnotetext{
${ }^{23}$ The slope $d p / d p^{*}$ of the interior Bertrand best-response function is $-\pi_{p p^{*}} / \pi_{p p}$, while the slope of the zero-import locus $\tilde{p}\left(p^{*}\right)$ is $-y_{p^{*}} / y_{p}$. It is then easy to show that the condition $y_{p^{*}} \pi_{p p}-y_{p} \pi_{p p^{*}}>0$ implies that $-y_{p^{*}} / y_{p}>-\pi_{p p^{*}} / \pi_{p p}$ : the zero-imports locus is steeper than the interior home best-response function.

${ }^{24}$ This property holds throughout the interval $\left(\hat{t}^{B}, \hat{t}^{C}\right)$, but at the end-points it holds only for changes in $t$ that move strictly inside the interval; that is, $\left.\frac{d W^{B}}{d t}\right|_{t=\hat{t}^{B},+}$ and $\left.\frac{d W^{B}}{d t}\right|_{t=\hat{t}^{C},-}$.
} 
the change in welfare for a small reduction in trade costs starting in autarky depends only on the change in consumption of the home good:

$$
\left.\frac{d W^{C}}{d t}\right|_{t=\widehat{t}^{C},-}=\left.(p-c) \frac{d x^{C}}{d t}\right|_{t=\hat{t}^{C},-}
$$

From (22), this is positive provided outputs are strategic substitutes; that is, a small reduction in trade costs starting at $t=\widehat{t}^{c}$ increases trade but reduces welfare. Since we have already seen in (38) that it increases welfare under Bertrand competition, this confirms that a Nimzowitsch Region exists when quantities are strategic substitutes.

We can go further and show that, even when quantities are strategic complements, so that welfare under Cournot competition rises for a small reduction in trade costs starting in autarky (i.e., the $W^{C}$ locus is downward-sloping at $t=\widehat{t}^{C}$ unlike in Figure 3), welfare is still higher locally under Bertrand competition, so equation (35) holds. Intuitively, even if $d x^{C} / d t$ is negative, it is still the case that $d x^{B} / d t$ is larger in absolute value in the neighborhood of $\hat{t}^{C}$. See Appendix B for the proof. Hence we can conclude:

Proposition 6. A Nimzowitsch Region always exists in the neighborhood of autarky.

Taken in conjunction with the results in (28), (30) and (38), this confirms that the qualitative features of welfare as a function of trade costs are the same with general demands as in the linear case. However, with general demands unlike with linear demands we cannot be sure that the Nimzowitsch region exists away from the neighborhood of autarky. Furthermore, unlike in the linear case, we cannot be certain that under Bertrand competition, welfare with trade is never lower than welfare under autarky. There is, however a special case in which we can be more definitive about both of these issues. So far, we have assumed that goods are differentiated, however it is interesting to consider the case of identical goods. With identical goods, under Bertrand competition, there are no imports for $t>0$. In other words $\widehat{t}^{B}=0$. In that case, under Bertrand competition below $\widehat{t}^{C}$, the marginal cost of the foreign firm is $c+t$ and the marginal cost of the home firm is $c$ so the home firm will set a price just below $c+t$ when $t>0$. (Here we assume as is standard, that the firms share the market when they set the same price). It is then immediate that, when goods are identical, we can never have losses from trade under Bertrand competition and also that a Nimzowitsch region exists for all trade costs in the interval $\left(0, \widehat{t}^{c}\right) .^{25}$

\section{Conclusion}

- In this article, we have compared changes in trade costs under Cournot and Bertrand competition in a common reciprocal-markets framework. We have shown that the qualitative effects of trade cost reductions are broadly similar in the two cases. In particular, welfare is typically Ushaped in trade costs, first falling (as home firms face more competition) and then rising (as prices fall and consumers gain). Moreover, the critical level of trade costs below which the possibility of trade affects the domestic firm's behavior is the same under both Cournot and Bertrand competition.

Nonetheless, there are important quantitative differences between the effects of trade cost changes in the two cases. These broadly reflect the fact that Bertrand competition is generally more competitive than Cournot competition. While this is known from previous work, we have identified three novel and important aspects of the comparison. First is that the pro-competitive effects of trade are stronger under Bertrand competition despite the fact that, for sufficiently high trade costs, the volume of trade is greater under Cournot competition. We call the region of parameter space in which this outcome obtains a "van-der-Rohe Region" since "less is more":

\footnotetext{
${ }^{25} \mathrm{We}$ are grateful to an anonymous referee for drawing our attention to this case.
} 
though imports are lower, welfare is higher under Bertrand competition. Second is that a potential rival can affect an incumbent's sales and profits under Bertrand competition even if no imports take place in equilibrium. Moreover, this has a sufficiently large effect on domestic prices and hence on consumer surplus that it leads to higher welfare. We call the region of parameter space in which this outcome obtains a "Nimzowitsch Region" since "the threat is stronger than the execution": even though imports are zero under Bertrand competition, the pro-competitive effect is sufficiently strong that welfare is higher than under Cournot competition. Third is that while under Cournot competition, trade can lead to lower welfare than autarky for some levels of trade costs we have shown that under Bertrand competition, for the case of linear demands, welfare with trade never falls below the autarky level regardless of the trade cost, number of countries or the degree of product differentiation.

As mentioned in the introduction, our model can be given a closed economy, technological catchup reinterpretation, as one with a technologically superior firm facing competitors that suffer from a cost disadvantage. Interpreted in this way there is a parameter range in which partial catchup reduces welfare. It can also be shown, with linear demands, that welfare for some levels of partial catchup under Cournot competition will fall below the monopoly level but that in the Bertrand case welfare is never lower than under monopoly.

Our analysis clearly has implications for empirical work. For one thing, it shows that the level of imports by itself is a poor measure of the extent to which home firms are exposed to foreign competition. Moreover, a change in foreign access costs may affect the behavior of a domestic firm even though imports themselves do not change much or may not even occur. This chimes with recent empirical work by Bao and Chen (2018), who use media reports of potential multinational investments to quantify threats to domestic firms from foreign competition, and show that incumbent firms change their behavior even when foreign entry does not occur. Similar considerations apply in closed-economy applications of our model: a high market share by itself need not imply that an incumbent firm is shielded from competition; it may be disciplined by potential competition from a higher-cost competitor, even though the latter's sales are low or non-existent. Further work is needed to devise empirical measures of these kinds of invisible competition and to quantify their practical relevance.

\section{Appendix A}

Proofs of Propositions 1-4 follow.

$\square \quad$ Comparative statics of $\boldsymbol{V}$ and $\boldsymbol{\Gamma}$. Recallingthe definition of $V^{B} \equiv-\frac{(n-1) e^{2}}{1+(n-2) e}$ from (10) in Section 3, we have,

$$
\frac{\partial V^{B}}{\partial n}=-\frac{e^{2}(1-e)}{(1+(n-2) e)^{2}}<0 \quad \text { and } \quad \frac{\partial V^{B}}{\partial e}=-(n-1) e \frac{2+(n-2) e}{(1+(n-2) e)^{2}}<0
$$

Hence, as a function of $n, V^{B}$ falls monotonically from its value of $-e^{2}$ in duopoly, $n=2$, to its limiting value of $-e$ as $n$ grows without bound. As a function of $e$, it falls monotonically from zero to -1 along the $e \in[0,1]$ interval.

Next we want to see how the competitiveness parameter $\Gamma$ responds to changes. The only ambiguity arises in the case of Bertrand competition, when $\Gamma^{B}=2+V^{B}+(n-1) e$. Differentiating with respect to $n$ and using (A1) yields:

$$
\frac{d \Gamma^{B}}{d n}=e+\frac{\partial V^{B}}{\partial n}=e\left(1-\frac{e(1-e)}{(1+(n-2) e)^{2}}\right)>0
$$

So the indirect effect of $n$ on the mode of conduct parameter, $V^{B}$ dampens but does not offset the direct effect of $n$ in raising $\Gamma$. Similarly, differentiating with respect to $e$ :

$$
\frac{d \Gamma^{B}}{d e}=n-1+\frac{\partial V^{B}}{\partial e}=(n-1) \frac{1+2(n-3) e+(n-2)(n-3) e^{2}}{(1+(n-2) e)^{2}}
$$

For $n \geq 3$ this is definitely positive. The only ambiguity arises at $n=2$, when (A3) simplifies to $1-2 e$. Hence the indirect effect of $e$ on $V^{B}$ dampens the direct effect of $e$ in raising $\Gamma^{B}$; but does not offset it except in the duopoly case when goods are close substitutes $(n=2$ and $e>0.5)$. 
$\square \quad$ Proof of Proposition 1: welfare levels in the $\left[\mathbf{0}, \widehat{\boldsymbol{t}}^{B}\right]$ Interval. In order to prove that $W^{B}$ is greater than $W^{C}$ in the $\left[0, \widehat{t}^{B}\right]$ interval, we wish to evaluate the response of welfare to a change in the mode of conduct parameter $V$ from (15). The change in home sales and in total sales in the home market can be written from (11) as follows:

$$
x=\frac{A}{b \Gamma}\left(1+\frac{(n-1) e}{2+V-e} \frac{t}{A}\right) \quad Q=\frac{A}{b \Gamma}\left(n-(n-1) \frac{t}{A}\right)
$$

These are decreasing in $V$ by inspection. Next, we determine the responsiveness of welfare to changes in $x$ and $Y$ :

$$
W_{x}=A-b x-b e Y=p-c \quad W_{Y}=A-b e x-b \frac{1}{n-1}(1+(n-2) e) Y-t=p^{*}-c-t
$$

As for the difference between them, this simplifies to:

$$
W_{x}-W_{Y}=t-b(1-e)(x-y)=\frac{1+V}{2+V-e} t
$$

Both $W_{x}-W_{Y}$ and $W_{Y}$ are strictly positive in the interior of the interval $\left(0, \widehat{t}^{B}\right)$. As for the end-points, $W_{Y}$ is strictly positive at $t=0$ and $W_{x}-W_{Y}$ is strictly positive at $t=\widehat{t}^{B}$. Substituting into (15) proves Proposition 1.

Proposition 2: The lower boundary of the vdR region. We wish to show that the lower boundary of the van-derRohe Region, denoted by $t^{R}$, is decreasing in both $n$ and $e$. Recall the expression for $t^{R}$ in (17). Using (12) to eliminate terms, this can be rewritten as follows:

$$
t^{R}=A \frac{\left(2-e+V^{B}\right)(2-e)}{e \Gamma^{C}+2\left(2-e+V^{B}\right)}
$$

where, from (10) and (12), $V^{B}=-\frac{(n-1) e^{2}}{1+(n-2) e}$ and $\Gamma^{C}=2+(n-1) e$. Recalling from the discussion following equation (A1) above, that $V^{B}$ must lie in the range $\left[-e^{2},-e\right]$, it follows that $2-e+V^{B}$ is positive.

Consider first how $t^{R}$ varies with $n$. Differentiating (A7) yields:

$$
\frac{d t^{R}}{d n}=\underbrace{\frac{\partial t^{R}}{\partial \Gamma^{C}}}_{-} \underbrace{\frac{\partial \Gamma^{C}}{\partial n}}_{+}+\underbrace{\frac{\partial t^{R}}{\partial V^{B}}}_{+} \underbrace{\frac{\partial V^{B}}{\partial n}}_{-}
$$

To confirm the signs of the individual terms, it is clear by inspection that $t^{R}$ is decreasing in $\Gamma^{C}$, which itself is increasing in $n$; hence the first expression on the right-hand-side is negative. As for the second expression, differentiating yields:

$$
\frac{\partial t^{R}}{\partial V^{B}}=A \frac{e(2-e) \Gamma^{C}}{\left(e \Gamma^{C}+2\left(2-e+V^{B}\right)\right)^{2}}>0
$$

and we have seen in equation (A1) that $V^{B}$ is decreasing in $n$. This confirms the signs of the last two terms in (A8), which completes the proof that $t^{R}$ is decreasing in $n$.

We can also establish the limiting values of the $t^{R}$ locus as $n$ varies. In the duopoly case, where $n=2$, (A7) reduces to a downward-sloping 45-degree line: $t^{R}=A(1-e)$, as illustrated in Figure 1. As for the other extreme, as $n \rightarrow \infty$, $\left.V^{B}\right|_{n \rightarrow \infty}=-e$ and $\left.\Gamma^{C}\right|_{n \rightarrow \infty}=\infty$ (for $e>0$ ). Hence it follows that:

$$
\left.t^{R}\right|_{n \rightarrow \infty}=\left.A \frac{2(1-e)(2-e)}{e \Gamma^{C}+2\left(2-e+V^{B}\right)}\right|_{n \rightarrow \infty}=0
$$

This confirms that the van-der-Rohe Region expands to fully crowd out the B region for large $n$.

Consider next how the boundary varies with $e$. Differentiating (A7) with respect to $e$ yields:

$$
\frac{d t^{R}}{d e}=\underbrace{\frac{\partial t^{R}}{\partial \Gamma^{C}}}_{-} \underbrace{\frac{\partial \Gamma^{C}}{\partial e}}_{+}+\underbrace{\frac{\partial t^{R}}{\partial V^{B}}}_{+} \underbrace{\frac{\partial V^{B}}{\partial e}}_{-}+\underbrace{\frac{\partial t^{R}}{\partial e}}_{-}
$$

The signs of the first four terms are straightforward as before, recalling from equation (A1) that $V^{B}$ is decreasing in $e$. As for the final term, inspecting (A7) it can be seen that the numerator is decreasing in $e$ and the denominator is increasing in $e$ (since $\Gamma^{C}>2$ ). It follows that $t^{R}$ is decreasing in $e$.

$\square \quad$ Proposition 3: Welfare levels in the $\left(\widehat{\boldsymbol{t}}^{B}, \widehat{\boldsymbol{t}}^{C}\right)$ interval. We want to show that, in the $\left(\widehat{t}^{B}, \widehat{t}^{C}\right)$ interval when $n \geq 2$, welfare is higher under Bertrand competition than under Cournot competition.

The first step is to write the level of welfare in general form:

$$
W=u(x, \mathbf{y})-c(x+Y)-t Y
$$


Using (6) to eliminate utility, and imposing symmetry across all countries, so $y=\frac{Y}{n-1}$, gives:

$$
W=A(x+Y)-\frac{1}{2} b\left((1-e)\left(x^{2}+\frac{1}{n-1} Y^{2}\right)+e(x+Y)^{2}\right)-t Y
$$

To evaluate this in a Cournot equilibrium, we use the expression for imports by firm from (11), specialized to the Cournot case, and the corresponding expression for home output:

$$
x=\frac{1}{b \Gamma^{C}}\left(A+\frac{(n-1) e}{2-e} t\right) \text { and } Y=\frac{n-1}{b \Gamma^{C}}\left(A-\frac{2}{2-e} t\right)
$$

Substituting into (A13) yields

$$
W^{C}=\frac{(3+(n-1) e)(n A-2(n-1) t)}{2 b\left(\Gamma^{C}\right)^{2}} A+(n-1) \frac{12+4(n-2) e-(n-1) e^{2}}{2 b(2-e)^{2}\left(\Gamma^{C}\right)^{2}} t^{2}
$$

By inspection, this is decreasing at free trade, and is always convex in $t$.

However, under Bertrand in the interval $\left(\widehat{t}^{B}, \widehat{t}^{C}\right)$, the zero-import constraint binds, then the foreign firms' best response is to charge a price equal to their marginal cost of serving the market, $c+t$. The zero-import constraint with symmetry among the foreign firms is $Y\left(p^{*}, p\right)=0$. Where:

$$
Y\left(p^{*}, p\right)=\frac{(n-1)}{1-e} \frac{(1-e) a-\left(p^{*}-e p\right)}{b(1+(n-1) e)}
$$

is aggregate imports. From (A16), the symmetric maximum foreign price consistent with zero imports as a function of the home price is:

$$
p^{*}=\tilde{p}^{*}(p)=(1-e) a+e p
$$

In interval the $\left(\widehat{t}^{B}, \widehat{t}^{C}\right)$, the home firm's best-response is to set its own price at the level such that the zero-import constraint just binds: from its perspective it operates on the inverse of (A17), which we denote by $p=\tilde{p}\left(p^{*}\right)=\frac{p^{*}-(1-e) a}{e}$.

As for the level of welfare under Bertrand competition, $W^{B}$, from (A13), with $Y=0$, this equals $W^{B}=A x-\frac{1}{2} b x^{2}$. Output in turn is obtained by combining $\tilde{p}\left(p^{*}\right)=\frac{p^{*}-(1-e) a}{e}$ with $p^{*}=c+t$ and substituting into $p=a-b x$ to obtain: $\left.x\right|_{Y=0}=\frac{A-t}{b e}$. By inspection, we see that $W^{B}$ is concave in $t$. It follows immediately that $W^{B}-W^{C}$ must be positive throughout the relevant interval $\left(\widehat{t}^{B}, \widehat{t}^{C}\right)$. First, since $W^{B}$ is concave in $t$ in this interval, and, as already shown, $W^{C}$ is convex in $t$, the difference $W^{B}-W^{C}$ must itself be concave in $t$. Next, note that this difference is strictly positive at the lower end-point, $t=\widehat{t}^{B}$, from Proposition 1, and that it is zero at the upper end-point, $t=\widehat{t}^{C}$, where the home firm is an unconstrained monopolist. It follows that $W^{B}$ is equal to or greater than $W^{C}$ throughout the interval, which confirms that it is indeed a Nimzowitsch Region as stated in Proposition 3.

Proposition 3: The width of the $\left[\widehat{\boldsymbol{t}}^{B}, \widehat{\boldsymbol{t}}^{C}\right]$ interval. Direct calculation from (12) shows that the width of the $\left[\widehat{t}^{B}, \widehat{t}^{C}\right]$ interval is:

$$
\widehat{t}^{C}-\widehat{t}^{B}=-\frac{e V^{B}}{2\left(2+V^{B}\right)} \geq 0
$$

This is decreasing in $V^{B}$, which in conjunction with (A1) gives the result in Proposition 3 that the region is increasing in $n$. To show how it varies with $e$, totally differentiate:

$$
\frac{d\left(\widehat{t}^{C}-\widehat{t}^{B}\right)}{d e}=\frac{\partial\left(\widehat{t}^{C}-\widehat{t}^{B}\right)}{\partial e}+\frac{\partial\left(\widehat{t}^{C}-\widehat{t}^{B}\right)}{\partial V^{B}} \frac{\partial V^{B}}{\partial e}
$$

The first term on the right-hand side is positive from (A18); the final two terms are both negative from (A18) and (A1), respectively. This proves the result in Proposition 3 that the region is increasing in $e$.

Proposition 4: Gains from trade. We first define $\tau \equiv{ }_{t}^{t}$ as the trade cost as a proportion of the prohibitive level. We can express welfare for given $V$ as a function of $\tau$. When (11) and (12) are combined with (14) it is clear that welfare $W(\tau)$ is a convex quadratic in $\tau$ for $\tau \in[0,1]$. The parameter combination $\frac{A^{2}}{b}$ is common to each term in $W(\tau)$ and this allows us to write $W(\tau)=\left(\alpha \tau^{2}-\beta \tau+\theta\right) \frac{A^{2}}{b}$, where $\alpha, \beta$ and $\theta$ are all positive. These are:

$$
\beta=(n-1) \underline{t} \frac{1}{\Gamma^{2}}(3+2 V+(n-1) e)
$$

where $\widehat{\underline{t}} \equiv \frac{1}{A} \widehat{t}$,

$$
\theta=\frac{n}{2} \frac{1}{\Gamma^{2}}(3+2 V+(n-1) e)
$$


and

$$
\alpha=\frac{1}{2+V}\left(1-\frac{1}{2} \frac{1}{2+V}\right)+\beta-\theta
$$

Welfare at autarky is obtained by substituting monopoly output, $x^{M}=\frac{A}{2 b}$ and $Y=0$ into (14) to get $W^{0}=\frac{3}{8} \frac{A^{2}}{b}$. The gains from trade can thus be written as $W(\tau)-W^{0}=\left(\alpha \tau^{2}-\beta \tau+\theta-\frac{3}{8}\right) \frac{A^{2}}{b}$. At given $\tau$ this expression has the same sign as:

$$
\Omega(\tau)=\alpha \tau^{2}-\beta \tau+\gamma
$$

where $\gamma=\theta-\frac{3}{8}$. This reaches a minimum at $\tau^{\min }=\frac{\beta}{2 \alpha}$ with a minimum value:

$$
\Omega\left(\tau^{\min }\right)=\frac{\beta^{2}}{4 \alpha}\left(\frac{4 \alpha \gamma}{\beta^{2}}-1\right)
$$

which takes the sign of the term in brackets. First note that this term is negative under Cournot as we can use the fact that at $\tau=1$ we are at uncontested autarky so $\Omega^{C}(1)=0=\alpha^{C}-\beta^{C}+\gamma^{C}$. Then using $\beta^{C}=\alpha^{C}+\gamma^{C}$ in $\left(4 \alpha^{C} \gamma^{C}-\left(\beta^{C}\right)^{2}\right)$ we get $-\left(\alpha^{C}-\gamma^{C}\right)^{2}<0$. This confirms that losses from trade occur at some trade costs under Cournot. The Bertrand case is much less immediate because $\Omega^{B}(1)>0$ due to the Nimzowitsch region.

The algebra is simplified when we rewrite the term in brackets in (A24) under Bertrand, $\frac{4 \alpha^{B} \gamma^{B}}{\left(\beta^{B}\right)^{2}}-1$ using $\phi_{\alpha} \equiv$ $2 \frac{\alpha^{B}}{\beta^{B}}-1$ and $\phi_{\gamma} \equiv 1-2 \frac{\gamma^{B}}{\beta^{B}}$. Then $\Omega^{B}\left(\tau^{\mathrm{min}}\right) \geq 0$ when

$$
\phi_{\alpha}-\phi_{\gamma}-\phi_{\alpha} \phi_{\gamma} \geq 0
$$

where:

$$
\phi_{\alpha}=\frac{\Gamma^{B}}{(n-1)\left(2+V^{B}-e\right)}\left(\Gamma^{B} \frac{\left(3+2 V^{B}\right)}{\left(2+V^{B}\right)\left(3+2 V^{B}+(n-1) e\right)}-1\right)
$$

and

$$
\phi_{\gamma}=\frac{\Gamma^{B}}{(n-1)\left(2+V^{B}-e\right)}\left(\Gamma^{B} \frac{3\left(2+V^{B}\right)}{4\left(3+2 V^{B}+(n-1) e\right)}-1\right)
$$

The use of (A26) and (A27) in (A25) and simplification using (10) allows us to write the condition for gains from trade at all trade costs under Bertrand when $0<e<1$ as: $\left(4+3 V^{B}\right)\left(2+V^{B}-e\right)-\left(1+V^{B}\right) K \geq 0$ where $K=\frac{2-e-9 e(1-e)+n e(2-3 e)}{3+(n-4) e}$. Since $4+3 V^{B}>0$ and $\left(2+V^{B}-e\right)-\left(1+V^{B}\right)=1-e>0$, gains from trade are guaranteed if:

$$
\left(4+3 V^{B}\right)-K=\frac{2}{(3+(n-4) e)(1+(n-2) e)}\left(5-13 e+n^{2} e^{2}-8 n e^{2}+6 n e+3 e^{3}+6 e^{2}\right)>0
$$

Clearly $\frac{2}{(3+(n-4) e)(1+(n-2) e)}$ is positive so it remains to check the sign of the expression $N(e, n) \equiv\left(5-13 e+n^{2} e^{2}-8 n e^{2}+\right.$ $\left.6 n e+3 e^{3}+6 e^{2}\right)$. At $n=2$ this reduces to $N(e, 2)=5-e-3(2-e) e^{2}$ which is positive for $0<e<1$. Furthermore, $N(e, n)$ is increasing in $n$ and so is always positive. Thus there can be no losses from trade under Bertrand competition.

\section{Appendix B}

Derivations of results 1-4 in section 4 and proof of proposition 6 follow.

$\square \quad$ Interior equilibria. We begin with the case of Cournot competition. Substituting from the expressions for output change in (22) and (25) into the general expression for welfare change in (26) yields an expression that cannot be signed in general. However, we can sign it unambiguously in special cases. First, in free trade, when $t=0$, what matters for the effect of trade costs on welfare is the effect on total domestic consumption: ${ }^{26}$

$$
\left.\frac{d W^{C}}{d t}\right|_{t=0}=(p-c)\left(\frac{d x^{C}}{d t}+\frac{d y^{C}}{d t}\right)-y=\frac{p-c}{\pi_{x x}+\pi_{x y}}-y<0
$$

So, an increase in trade costs at $t=0$ reduces welfare. This gives result [1] in equation (28) in the text.

Second, we can sign the effect of trade costs on welfare at the prohibitive trade cost $\widehat{t}^{C}$. At this point, we have $p^{*}-c-t=0$ and $y=x^{*}=0$ which when combined with (26) yield:

$$
\left.\frac{d W^{C}}{d t}\right|_{t=\hat{t}^{c}}=(p-c) \frac{d x^{C}}{d t}=-\frac{p-c}{\Delta} \pi_{x y}
$$

\footnotetext{
${ }^{26}$ Recall from Lemma 3 that the denominator $\pi_{x x}+\pi_{x y}$ is negative in a symmetric equilibrium.
} 
This gives result [3] in equation (30) in the text. We can conclude that, under Cournot competition, a small fall in the trade cost from the prohibitive level, $\widehat{t}^{C}$, reduces welfare if and only if outputs are strategic substitutes.

Next we consider Bertrand competition. At $t=0$ we can make use of the symmetry of the model to obtain: ${ }^{27}$

$$
\left.\frac{d W^{B}}{d t}\right|_{t=0}=(p-c)\left(\frac{d x^{B}}{d t}+\frac{d y^{B}}{d t}\right)-y=\frac{p-c}{\pi_{p p}+\pi_{p p^{*}}}\left(x_{p}+x_{p^{*}}\right) y_{p^{*}}-y<0 .
$$

This gives result [2] in equation (28) in the text. Hence a small increase in trade costs starting at zero reduces welfare. At $t=\widehat{t}^{B}$, the volume of trade is zero and the effect of a local change in the trade cost is:

$$
\left.\frac{d W^{B}}{d t}\right|_{t=\tilde{t}^{B},-}=(p-c) \frac{d x^{B}}{d t}=\frac{p-c}{\widetilde{\Delta}}\left(x_{p^{*}} \pi_{p p}-x_{p} \pi_{p p^{*}}\right) y_{p^{*}}
$$

which is positive if $x_{p^{*}} \pi_{p p}-x_{p} \pi_{p p^{*}}$ is negative, the same condition we found above for home sales to be increasing in the trade cost, $d x^{B} / d t>0$. Note that this is the left-hand derivative at $t=\widehat{t}^{B}$. This gives result [4] in equation (30) in the text.

$\square \quad$ The Nimzowitsch region: proof of Proposition 6. We have shown in the text that, in Cournot competition, welfare falls as trade costs fall in the neighborhood of autarky if and only if goods are strategic substitutes, $\left.\frac{d W^{C}}{d t}\right|_{t=t^{c}}>0$. This proves that a Nimzowitsch Region exists in this case. Can we go further and prove that it must also exist under strategic complements? In this case, the signs of output and welfare change in Cournot competition are reversed: $\left.\frac{d x^{C}}{d t}\right|_{t=\hat{t}^{c}}<$ 0 and so $\left.\frac{d W^{C}}{d t}\right|_{t=t^{C}}<0$. However, we can show that the same ranking between the changes in Cournot and Bertrand competition holds as in the case of strategic substitutes. To see this, recall that the foreign firm's first-order condition is $p^{*}(y, x)-c+y p_{y}^{*}(y, x)=t$ throughout the Cournot region. Differentiating this and evaluating it at $y=0$ gives:

$$
\left.2 p_{y}^{*}(0, x) \frac{d y^{C}}{d t}\right|_{t=\hat{t}^{C}}+\left.p_{x}^{*}(0, x) \frac{d x^{C}}{d t}\right|_{t=\hat{t}^{C}}=1
$$

Hence, recalling from (37) that $\frac{d x^{B}}{d t}=\frac{1}{p_{x}^{*}(0, x)}$, we have:

$$
\left.\frac{d x^{C}}{d t}\right|_{t=\hat{t}^{C}}=\frac{1}{p_{x}^{*}(0, x)}\left(1-\left.2 p_{y}^{*}(0, x) \frac{d y^{C}}{d t}\right|_{t=\widehat{t}^{C}}\right)=\left.\frac{d x^{B}}{d t}\right|_{t=\widehat{t}^{C}}-\left.\frac{2 p_{y}^{*}(0, x)}{p_{x}^{*}(0, x)} \frac{d y^{C}}{d t}\right|_{t=\widehat{t}^{C}}
$$

Hence we can conclude that, at $t=\widehat{t}^{C}$, home consumption increases faster with the trade cost under Cournot than under Bertrand competition:

$$
\left.\frac{d x^{C}}{d t}\right|_{t=t^{C}}-\left.\frac{d x^{B}}{d t}\right|_{t=t^{C}}=-\left.\frac{2 p_{y}^{*}(0, x)}{p_{x}^{*}(0, x)} \frac{d y^{C}}{d t}\right|_{t=t^{C}}>0
$$

Invoking (36) and (39) shows the same is true of welfare:

$$
\left.\frac{d W^{C}}{d t}\right|_{t=\hat{t}^{C}}-\left.\frac{d W^{B}}{d t}\right|_{t=\hat{t}^{C}}=-\left.(p(x, 0)-c) \frac{2 p_{y}^{*}(0, x)}{p_{x}^{*}(0, x)} \frac{d y^{C}}{d t}\right|_{t=T^{C}}>0
$$

which proves the result that, as trade costs fall in the neighborhood of autarky $\left(t=\widehat{t}^{c}\right)$, welfare rises faster under Bertrand competition than under Cournot competition, when goods are strategic complements.

\section{Acknowledgment}

\section{- Open access funding provided by IReL.}

\section{References}

Anderson, S.P., Donsimoni, M.-P., And Gabszewicz, J.J. “Is International Trade Profitable to Oligopolistic Industries?” International Economic Review, Vol. 30(4) (1989), pp. 725-733.

Arkolakis, C., Costinot, A., Donaldson, D., and Rodríguez-Clare, A. "The Elusive Pro-Competitive Effects of Trade." Review of Economic Studies, Vol. 86(1) (2018), pp. 46-80.

Arkolakis, C., Costinot, A., and Rodríguez-Clare, A. "New Trade Models, Same Old Gains?” American Economic Review, Vol. 102(1) (2012), pp. 94-130.

BAo, C. AND ChEn, M. "Foreign Rivals Are Coming to Town: Responding to the Threat of Foreign Multinational Entry." American Economic Journal: Applied Economics, Vol. 10(4) (2018), pp. 120-57.

Bernhofen, D.M. "Product Differentiation, Competition, and International Trade." Canadian Journal of Economics, Vol. 34(4) (2001), pp. 1010-1023.

Brander, J. And Krugman, P. “A 'Reciprocal Dumping’ Model of International Trade.” Journal of International Economics, Vol. 15(3-4) (1983), pp. 313-321.

\footnotetext{
${ }^{27}$ Recall from Lemma 3 that the denominator $\pi_{p p}+\pi_{p p^{*}}$ is negative in a symmetric equilibrium.
} 
Brander, J.A. "Intra-Industry Trade in Identical Commodities.” Journal of International Economics, Vol. 11(1) (1981), pp. 1-14.

Brander, J.A. And Spencer, B.J. “Export Subsidies and International Market Share Rivalry.” Journal of International Economics, Vol. 18(1) (1985), pp. 83-100.

Brander, J.A. AND Spencer, B.J. "Intra-Industry Trade with Bertrand and Cournot Oligopoly: The Role of Endogenous Horizontal Product Differentiation.” Research in Economics, Vol. 69(2) (2015), pp. 157-165.

Clarke, R. and Collie, D.R. "Product Differentiation and the Gains from Trade under Bertrand Duopoly." Canadian Journal of Economics, Vol. 36(3) (2003), pp. 658-673.

Collie, D.R. ANd Le, V.P.M. "Product Differentiation, the Volume of Trade and Profits under Cournot and Bertrand Duopoly." International Journal of the Economics of Business, Vol. 22(1) (2015), pp. 73-86.

Costinot, A. and Rodríguez-Clare, A. "Trade Theory with Numbers: Quantifying the Consequences of Globalization." In G. Gopinath, E. Helpman and K. Rogoff, eds., Handbook of International Economics. Amsterdam, The Netherlands: Elsevier, 2014, pp. 197-261.

Deneckere, R. AND Davidson, C. "Incentives to Form Coalitions with Bertrand Competition." RAND Journal of Economics, Vol. 16(4) (1985), pp. 473-486.

Dixit, A. “The Role of Investment in Entry-Deterrence.” Economic Journal, Vol. 90(357) (1980), pp. 95-106.

Dixit, A. “Comparative Statics for Oligopoly.” International Economic Review, Vol. 27(1) (1986), pp. 107-122.

Eaton, J. and Grossman, G.M. "Optimal Trade and Industrial Policy Under Oligopoly." Quarterly Journal of Economics, Vol. 101(2) (1986), pp. 383-406.

ERLEI, M. "Some Forgotten Equilibria of the Bertrand Duopoly." TUC Working Papers in Economics no. 0004, Department of Economics, Technical University Clausthal, 2002.

Fershtman, C. AND JudD, K.L. "Equilibrium Incentives in Oligopoly.” American Economic Review, Vol. 77(5) (1987), pp. 927-940.

Freund, C. And Pierola, M.D. “Export Superstars.” Review of Economics and Statistics, Vol. 97(5) (2015), pp. 10231032 .

Friberg, R. AND GANDSLANDT, M. “An Empirical Assessment of the Welfare Effects of Reciprocal Dumping.” Journal of International Economics Vol. 70(1) (2006), pp. 1-24.

Friberg, R. And Gandslandt, M. "Reciprocal Dumping with Product Differentiation." Review of International Economics Vol. 16(5) (2008), pp. 942-954.

Friedman, J.W. Oligopoly and the Theory of Games. Amsterdam, The Netherlands: North-Holland, 1977.

Fudenberg, D. And Tirole, J. "The Fat-Cat Effect, the Puppy-Dog Ploy, and the Lean and Hungry Look." American Economic Review, Vol. 74(2) (1984), pp. 361-366.

Head, K. and Spencer, B.J. "Oligopoly in International Trade: Rise, Fall and Resurgence." Canadian Journal of Economics, Vol. 50(5) (2017), pp. 1414-1444.

Holmes, T.J., Hsu, W., AND LeE, S. “Allocative Efficiency, Mark-ups, and the Welfare Gains from Trade.” Journal of International Economics, Vol. 94(2) (2014), pp. 195-206.

Kreps, D.M. and Scheinkman, J.A. "Quantity Precommitment and Bertrand Competition Yield Cournot Outcomes." Bell Journal of Economics, Vol. 14(2) (1983), pp. 326-337.

Leahy, D. AND NeARY, J.P. “Oligopoly and Trade.” In D. Bernhofen, R. Falvey, D. Greenaway, and U. Kreickemeier, eds., Palgrave Handbook of International Trade. Basingstoke, UK: Palgrave Macmillan, 2011, pp. 197-235.

Maggi, G. "Strategic Trade Policies with Endogenous Mode of Competition." American Economic Review, Vol. 86(1) (1996), pp. 237-258.

Mayer, T. and Ottaviano, G.I. “The Happy Few: The Internationalisation of European Firms.” Intereconomics: Review of European Economic Policy, Vol. 43(3) (2008), pp. 135-148.

Melitz, M.J. And Redding, S.J. "New Trade Models, New Welfare Implications." American Economic Review, Vol. 105(3) (2015), pp. 1105-1146.

Mrázová, M. “Trade Agreements When Profits Matter.” Unpublished manuscript, Department of Economics, University of Surrey, 2011.

NeARY, J.P. And Tharakan, J. "International Trade with Endogenous Mode of Competition in General Equilibrium." Journal of International Economics, Vol. 86(1) (2012), pp. 118-132

Salant, S.W., Switzer, S., and Reynolds, R.J. "Losses From Horizontal Merger: The Effects of an Exogenous Change in Industry Structure on Cournot-Nash Equilibrium." Quarterly Journal of Economics, Vol. 98(2) (1983), pp. 185199.

Singh, N. And Vives, X. "Price and Quantity Competition in a Differentiated Duopoly." RAND Journal of Economics, Vol. 15(4) (1984), pp. 546-554.

SKLIVAS, S.D. "The Strategic Choice of Managerial Incentives." RAND Journal of Economics, Vol. 18(3) (1987), pp. $452-458$.

Vickers, J. “Delegation and the Theory of the Firm.” Economic Journal, Vol. 95 (1985), pp. 138-147.

Vives, X. "On the Efficiency of Bertrand and Cournot Equilibria with Product Differentation." Journal of Economic Theory, Vol. 36(1) (1985), pp. 166-175.

Zanchettin, P. "Differentiated Duopoly with Asymmetric Costs." Journal of Economics \& Management Strategy Vol. 15(4) (2006), pp. 999-1015. 